\title{
Regime Switches, Agents' Beliefs, and Post-World War II U.S. Macroeconomic Dynamics
}

\author{
Francesco Bianchi
}

Duke University

July 2012

ERID Working Paper Number 120

This paper can be downloaded without charge from the Social Science Research Network Electronic Paper Collection: http://ssrn.com/abstract $=1990478$

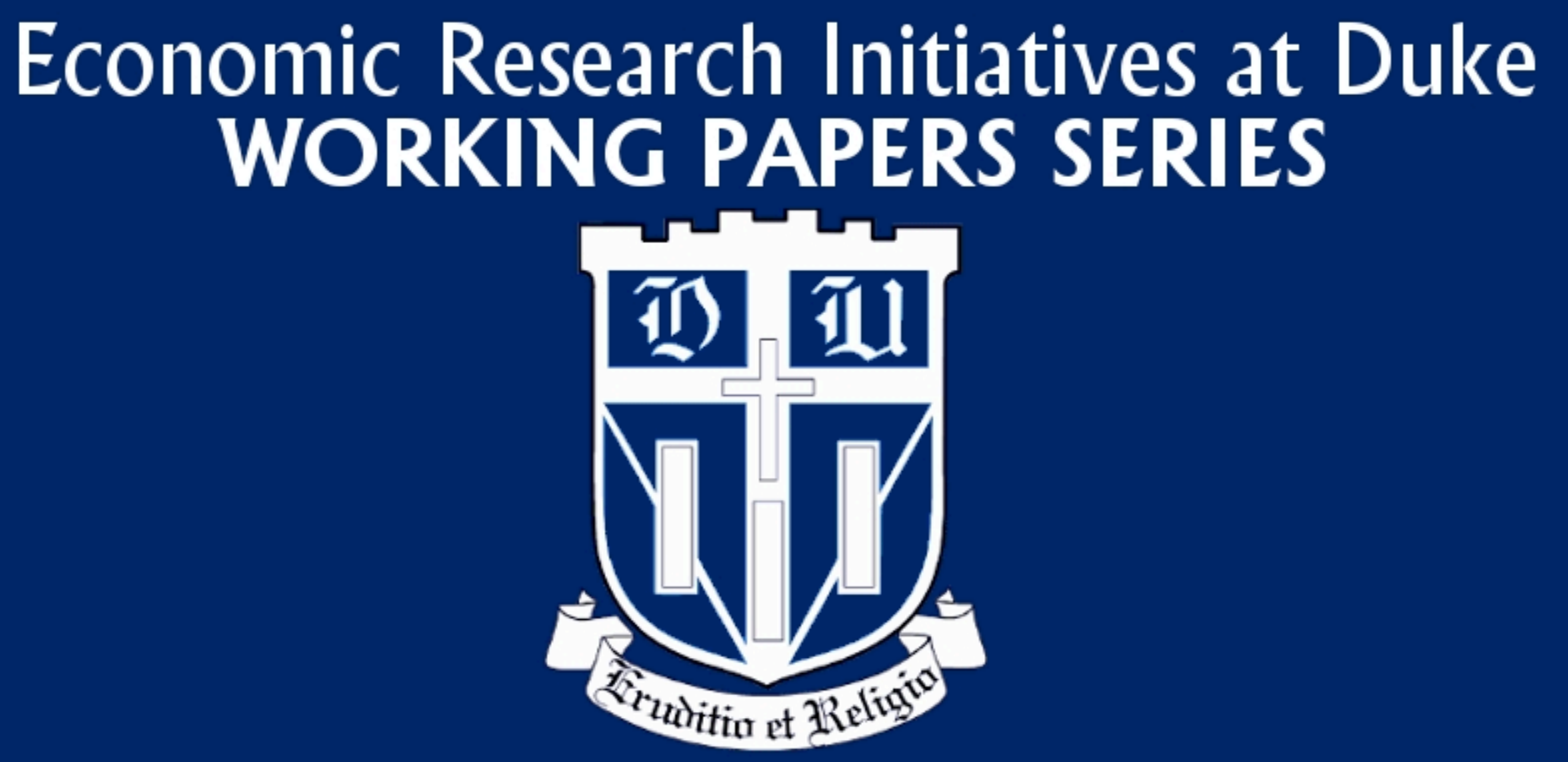




\title{
Regime Switches, Agents' Beliefs, and Post-World War II U.S. Macroeconomic Dynamics*
}

\author{
Francesco Bianchi \\ Duke University
}

First draft: June 2008

This draft: July 2012

\begin{abstract}
The evolution of the U.S. economy over the last 55 years is examined through the lens of a micro-founded model that allows for changes in the behavior of the Federal Reserve and in the volatility of structural shocks. Agents are aware of the possibility of regime changes and their beliefs matter for the law of motion underlying the macroeconomy. Monetary policy is identified by repeated fluctuations between a Hawk and a Dove regime, with the latter prevailing in the ' 70 s and during the recent crisis. To explore the role of agents' beliefs I introduce a new class of counterfactual simulations: beliefs counterfactuals. If, in the '70s, agents had anticipated the appointment of an extremely conservative Chairman, inflation would have been lower and the inflationoutput trade-off more favorable. The large drop in inflation and output at the end of 2008 would have been mitigated if agents had expected the Federal Reserve to be exceptionally active in the near future.
\end{abstract}

${ }^{*}$ I would like to thank the editor Enrique Sentana and three anonymous referees for exceptionally thoughtful comments. I am deeply indebted to Chris Sims for his guidance and advice. I am also grateful to Mark Watson, Efrem Castelnuovo, Cosmin Ilut, Nobuhiro Kiyotaki, David Lucca, Esteban Rossi-Hansberg, Barbara Rossi, Tom Sargent, Tao Zha, and all seminar participants at Princeton University, the Board of Governors, the Federal Reserve Bank of Chicago, the New York Area Workshop on Monetary Policy, University of Pennsylvania, University of Virginia, Northwestern University, Duke University, UCLA, New York University, Philadelphia Fed, Penn State, CREI-Pompeu Fabra, University of Bern, NBER Summer Institute, Society for Economic Dynamics Annual Meeting, Richmond Fed, College of William and Mary, Johns Hopkins University, CEMFI, for useful suggestions and comments. Part of this paper was completed while the author was visiting the Board of Governors, whose hospitality is gratefully acknowledged. Correspondence: Duke University, 213 Social Sciences Building, Box 90097, Durham, NC 27708-0097. E-mail: francesco.bianchi@duke.edu. 


\section{Introduction}

The importance of agents' expectations in determining equilibrium outcomes became apparent to macroeconomists following the rational expectations hypothesis revolution that occurred in the '70s. Practitioners learned that empirical work revolving around policy changes cannot abstract from modeling agents' expectations about these very same changes. With this lesson in mind, this paper aims to explain the evolution of macroeconomic dynamics over the last 55 years, taking into account not only the possibility of regime switches in the behavior of the Federal Reserve but also agents' beliefs around these changes. To this end, a general equilibrium model in which the behavior of the Federal Reserve is allowed to change over time is fitted to the data. In such a model, regime changes are regarded as stochastic and reversible, agents are aware of this, and their beliefs matter for the law of motion governing the evolution of the economy.

Before describing the results, I shall contextualize them starting with a brief description of the events that this paper intends to interrelate. Figure 1 shows the series for output growth, inflation, and the federal funds rate (FFR) for the period 1954:Q3-2009:Q2. The shaded areas represent the NBER recessions and the vertical lines mark the appointment dates of the Federal Reserve Chairmen. While relatively low and stable over the early years of the sample, inflation started rising during the late '60s and spun out of control in the late '70s. At the same time the economy experienced a deep recession following the oil crisis of 1974. During the first half of the ' 80 s, inflation went back to the levels that were prevailing before the '70s at the cost of two severe recessions. From the mid-80s until the recent financial crisis, the economy has been characterized by remarkable economic stability. Economists refer to this last period as "Great Moderation." The "Great Inflation" is often used to label the turmoil of the '70s, while the "Great Recession" has become a popular way to indicate the recent contraction. The sharp contrast between these periods is evident. Understanding the causes of these remarkable changes is crucial, particularly now that policymakers are facing a severe slowdown, along with concerns about the path of future inflation.

Economists who tend to establish a clear link between the behavior of the Fed and the performance of the economy would argue that the sharp contrast between the '70s and the twenty years that preceded the most recent recession is the result of a substantial switch in the anti-inflationary stance of the Federal Reserve ("Good Policy"). The two most prominent examples of this school of thought are Clarida et al. (2000) and Lubik and Schorfheide (2004). On the other hand, several other authors find little evidence in favor of changes in the parameters describing policy rules and ample evidence supporting the idea that, at least to some extent, the Great Moderation was due to "Good Luck." As strong advocates of 

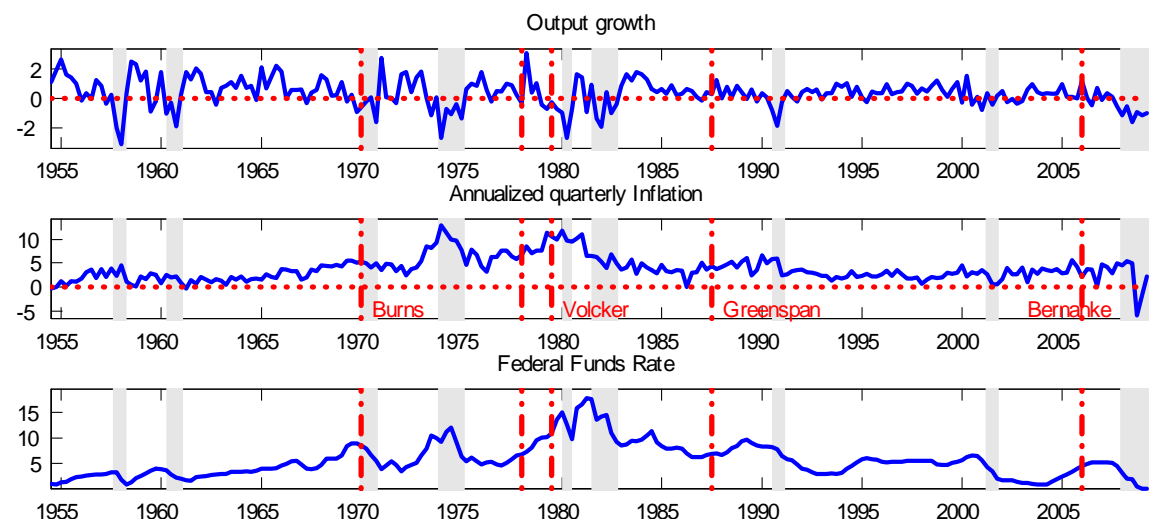

Figure 1: Output growth, inflation, and FFR (1954:Q3-2009:Q2) in percentage points. The shaded areas represent NBER recessions, while the vertical lines mark the appointment dates of the Fed Chairmen.

this alternative explanation, Sims and Zha (2006) use a Markov-switching VAR and identify changes in the volatilities of the structural disturbances as the key driver behind the stabilization of the U.S. economy. ${ }^{1}$ Finally, the jury is still out when it comes to the behavior of the Federal Reserve in the aftermath of the recent crisis.

Thus, the first contribution of this paper is to shed new light on this controversy. I consider a dynamic stochastic general equilibrium model in which the Taylor rule parameters characterizing the behavior of the Federal Reserve and the volatilities of the structural shocks are allowed to change over time. These changes are modeled as two independent Markovswitching (MS) processes in order to accommodate the two competing explanations. In the model, agents are aware of the possibility of regime changes. Thus, the law of motion of the variables of interest depends not only on the traditional microfounded parameters but also on the beliefs around alternative regimes.

Two main results emerge from the estimates. First, the model supports the idea that U.S. monetary policy was subject to regime changes. The best performing model is one in which the Taylor rule is allowed to move between a Hawk and a Dove regime. The former implies a strong response to inflation and little concern for output growth, whereas the latter comes with a weak response to inflation. From this point of view, the results differ from the existing literature that finds little evidence in favor of parameter instabilities beyond that implied by heteroskedasticity. Second, the idea that U.S. economic history can be divided into preand post-Volcker turns out to be misleading. Surely the results corroborate the widespread belief that the appointment of Volcker marked a change in the stance of U.S. policymakers

\footnotetext{
${ }^{1}$ Support for the Good Policy interpretation is also provided by Boivin and Giannoni (2006), whereas Bernanke and Mihov (1998), Leeper and Zha (2003), Stock and Watson (2003), Canova and Gambetti (2004), Kim and Nelson (2004), Cogley and Sargent (2006), and Primiceri (n.d.) provide little evidence in favor of the view that the monetary policy rule has changed drastically.
} 
toward inflation. However, the behavior of the Federal Reserve cannot be described by a one-time-only regime change. Specifically, the Dove regime was certainly in place during the '70s but also during the recent crisis, and with high probability during the second half of the '60s. In this respect, the results corroborate the view of Sims and Zha (2006) that monetary policy regime changes are better modeled as stochastic and reversible.

The second and main contribution of the paper revolves around the role of agents' beliefs in explaining the Great Inflation. First, using a counterfactual simulation in which the Hawk regime is assumed to be in place throughout the sample, I show that the Fed could have mitigated the rise of inflation in the ' $70 \mathrm{~s}$ but the cost in terms of output would have been significant. Then, I introduce a new class of counterfactual simulations that revolve around agents' beliefs, taking full advantage of the potential of MS rational expectations models. I point out that, in the '70s, the Fed was probably facing a severe credibility problem and beliefs about alternative monetary policy regimes were playing a crucial role. To address this hypothesis, I introduce a third regime, the Eagle regime, that is even more hawkish than the Hawk regime. This regime is meant to describe the behavior of an extremely conservative Chairman. It turns out that if agents had assigned a relatively large probability to this hypothetical regime, inflation in the '70s would have been substantially lower, independent of whether or not the Eagle regime occurred. Quite interestingly, the sacrifice ratio, i.e., the toll in terms of lower output for a given reduction in inflation, would have been lower compared to the case in which monetary policy is assumed to be constantly hawkish.

Finally, the model offers interesting insights about the Great Recession. First, the sudden drop in investment and inflation at the end of 2008 is captured by the interaction between an adverse shock to the efficiency of investment and the Dove regime. Interestingly, the probability of the Dove regime starts increasing in 2005, well before policymakers became aware of the incumbent crisis. Second, counterfactual simulations show that if the Fed had been more reactive to economic conditions, or if agents had attached a large probability to moving to a very active regime such as the Eagle regime, the impact of the shock would have been mitigated. ${ }^{2}$ Furthermore, while the former scenario might be hard to implement when approaching the zero lower bound, the latter is less problematic given that it does not involve an immediate change in the conduct of monetary policy.

These results point toward two important conclusions. First, beliefs about alternative regimes can go a long way in modifying equilibrium outcomes. In a Markov-switching DSGE (MS-DSGE) model, the effective sacrifice ratio faced during episodes of high inflationary pressure depends on the alternative scenarios that agents have in mind. If agents anticipate

\footnotetext{
${ }^{2}$ Here the use of the words active and passive follows Leeper (1991). Monetary policy is active when the interest rate is highly responsive to inflation.
} 
a change in monetary policy implying a more anti-inflationary stance, expected inflation decreases and, through the expectation channel, causes inflation to decrease today. Second, monetary policy does not need to be hawkish all the time in order to achieve the goal of low and stable inflation. What is truly necessary is a strong commitment to bringing the economy back to equilibrium as soon as adverse shocks disappear. It seems that in the '70s the main problem was not simply that the Fed was accommodating a series of adverse shocks, but rather that there was a lack of commitment to restoring equilibrium once the economy had gone through the peak of the crisis. In this context, the Volcker disinflation might have been important exactly because it made such a commitment credible. In a similar way, during the recent crisis the Federal Reserve might have experienced problems in convincing agents that exceptional measures would have been implemented in order to restore the equilibrium.

A MS-DSGE model represents a promising tool to better understand changes in the macroeconomy because it allows for stochastic and reversible regime changes of microfounded structural parameters, therefore combining the advantages of the VAR and DSGE literature and addressing the concerns recently raised by Benati and Surico (2009). At the same time, and this is the novelty of this new class of models, expectations are formed by taking into account the possibility of regime changes. Consequently, counterfactual simulations are more meaningful and more robust to the Lucas critique (Lucas (1976)). FernándezVillaverde and Rubio-Ramírez (2007) and Fernández-Villaverde et al. (2010) consider a valid alternative to model parameter instability, studying models with smoothly time-varying structural parameters that are solved using perturbation methods and estimated with particle filtering. The most notable innovation of the current paper consists of investigating the role of agents' beliefs through counterfactual simulations of beliefs. These beliefs counterfactuals are new in the literature and do not necessarily require modifying the current behavior of policymakers, while they always involve a change in agents' beliefs about future events.

To the best of my knowledge, this paper represents the first attempt to estimate a medium-size DSGE model with MS regime changes in structural parameters and stochastic volatilities. Justiniano and Primiceri (2008), Laforte (2005), and Liu et al. (2011) have considered DSGE models with stochastic volatilities, but in these papers, structural parameters are time-invariant. Davig and Doh (2008) allow for monetary policy switches in a purely forward-looking small-size New Keynesian model to explain changes in the persistence of inflation. The focus of the two papers is clearly different: Davig and Doh (2008) do not conduct any kind of counterfactual exercise and do not investigate the role of agents' beliefs.

The content of this paper can be summarized as follows. Section 2 illustrates the model and the estimation strategy. Section 3 presents the results. Section 4 shows that the data favor a model with regime changes in monetary policy. Section 5 concludes. 


\section{The Benchmark Model}

As explained in the introduction, the model considered in this paper allows the behavior of the central bank and stochastic volatilities to evolve over time. These changes are modeled as two independent MS processes. I introduce two unobserved state variables $\xi_{t}^{s p}$ and $\xi_{t}^{v o}$, capturing the monetary policy regime and the volatility regime that are in place at time $t$. Here and in what follows, $s p$ and $v o$ stand, respectively, for structural parameters and volatilities. The unobserved states take on a finite number of values $j_{s p}=1, \ldots, m_{s p}$ and $j_{v o}=1, \ldots, m_{v o}$ and evolve according to the transition matrices $H^{s p}$ and $H^{v o}$, respectively.

\subsection{The model}

In what follows, I describe the model. This is based on the work of Christiano et al. (2005).

Households: The preferences of the representative household are given by:

$$
E_{t} \sum_{s=0}^{\infty} \beta^{s} \zeta_{C, t+s}\left\{\log \left(C_{t+s}-\Phi \bar{C}_{t+s-1}\right)-\left(1+\sigma_{L}\right)^{-1} L_{t+s}^{1+\sigma_{L}}\right\}
$$

where $\beta$ is the discount rate, $\Phi$ is an external habit parameter, $C_{t}$ denotes consumption, $\bar{C}_{t}$ is average consumption in the economy, $L_{t}$ denotes the labor service supplied by the household, and $\sigma_{L}$ is the inverse of the Frisch labor supply elasticity. The variable $\zeta_{C, t}$ represents an intertemporal preference shock with mean one and time series representation:

$$
\log \left(\zeta_{C, t}\right)=\rho_{\zeta_{C}} \log \left(\zeta_{C, t-1}\right)+\sigma_{\zeta_{C}}\left(\xi_{t}^{v o}\right) \varepsilon_{\zeta_{C}, t}, \varepsilon_{\zeta_{C}, t} \sim N(0,1) .
$$

Households own the physical stock of capital and rent out capital services, $K_{t}$, to a competitive capital market at the rate $P_{t} r_{t}^{k}$, by selecting the capital utilization rate $u_{t}$ : $K_{t}=u_{t} \bar{K}_{t-1}$, where $\bar{K}_{t}$ measures physical capital at the end of period $t$. Increased utilization requires increased maintenance costs in terms of investment goods per unit of physical capital measured by the function $a\left(u_{t}\right)$. The function $a($.$) is increasing, convex, and equal to zero$ when $u_{t}=u$, where $u=1$ is the steady-state value for utilization. ${ }^{3}$ As shown by Altig et al. (2011), in the linearized solution of the model, only the ratio $a^{\prime \prime}(1) / a^{\prime}(1)=\sigma_{A}$ is relevant for the law of motion of the economy and this is the parameter that will be estimated.

The household accumulates physical capital subject to the following law of motion:

$$
\bar{K}_{t}=(1-\delta) \bar{K}_{t-1}+\left[1-S\left(\zeta_{I, t}\left[I_{t} / I_{t-1}\right]\right)\right] I_{t}
$$

where $I_{t}$ is period $t$ investment and the function $S$ reflects adjustment costs in investment.

\footnotetext{
${ }^{3}$ All the variables of the model without a time index should be interpreted as steady-state values.
} 
The function $S$ is convex and in the steady state $S=0=S^{\prime}$. The variable $\zeta_{I, t}$ represents a mean one shock to the marginal efficiency of investment and follows the process:

$$
\log \left(\zeta_{I, t}\right)=\rho_{\zeta_{I}} \log \left(\zeta_{I, t-1}\right)+\sigma_{\zeta_{I}}\left(\xi_{t}^{v o}\right) \varepsilon_{\zeta_{I}, t}, \quad \varepsilon_{\zeta_{I}, t} \sim N(0,1)
$$

The household's budget constraint is:

$$
P_{t} C_{t}+P_{t}\left(\zeta \Upsilon, t \Upsilon^{t}\right)^{-1} I_{t}+B_{t}=B_{t-1} R_{t-1}+P_{t} \bar{K}_{t-1}\left[r_{t}^{k} u_{t}-a\left(u_{t}\right) \Upsilon^{-t}\right]+W_{t} L_{t}-T_{t} P_{t}
$$

where $W_{t}$ is the wage rate, $B_{t}$ is holdings of government bonds, $R_{t}$ is the gross nominal interest rate, and $T_{t}$ is net lump-sum taxes. The cost, in consumption units, of one unit of the investment good is declining over time $\chi_{t}=\left(\zeta_{\Upsilon, t} \Upsilon^{t}\right)^{-1}$ (see below for further details). Since the currency price of the consumption good is $P_{t}$, the currency price of a unit of investment good is $P_{t} \chi_{t}=P_{t}\left(\zeta_{\Upsilon, t} \Upsilon^{t}\right)^{-1}$. Note also that the utilization cost, $a\left(u_{t}\right) \Upsilon^{-t}$, is declining over time. This is necessary in order to ensure balanced growth. The variable $\zeta_{\Upsilon, t}$ captures a stationary disturbance to the relative price of investment and follows the process:

$$
\log \zeta_{\Upsilon, t}=\rho_{\zeta_{\Upsilon}} \log \zeta_{\Upsilon, t-1}+\sigma_{\zeta_{\Upsilon}}\left(\xi_{t}^{v o}\right) \varepsilon_{\zeta_{\Upsilon}, t}, \varepsilon_{\zeta_{\Upsilon}, t} \sim N(0,1)
$$

Firms: The final output in this economy is produced by a representative final good firm that combines a continuum of intermediate goods $Y_{j, t}$ in the unit interval by using the following linear homogeneous technology:

$$
Y_{t}=\left[\int_{0}^{1} Y_{j, t}^{1 / \lambda_{f}} d j\right]^{\lambda_{f}}
$$

where $\lambda_{f}$ is the markup of price over marginal cost for intermediate goods firms. Profit maximization and the zero profit condition lead to the demand function for good $j$ :

$$
Y_{j, t}=Y_{t}\left(P_{j, t} / P_{t}\right)^{-\lambda_{f} /\left(\lambda_{f}-1\right)}
$$

and the price of final goods is obtained integrating over the intermediate good prices:

$$
P_{t}=\left[\int_{0}^{1} P_{j, t}^{1 /\left(1-\lambda_{f}\right)} d j\right]^{1-\lambda_{f}}
$$

The intermediate good $j$ is produced by a price-setting monopolist using the following production function:

$$
Y_{j, t}=\max \left\{K_{j, t}^{\alpha}\left(A_{t} L_{j, t}\right)^{1-\alpha}-F z_{t}^{*}, 0\right\}
$$


where $F$ is a fixed cost and $K_{j, t}$ and $L_{j, t}$ denote the services of capital and homogeneous labor employed by firm $j . F$ is chosen so that steady-state profits are equal to zero. The intermediate goods firms are competitive in factor markets, where they confront a rental rate of capital $P_{t} r_{t}^{k}$ and a wage rate $W_{t}$. The variable, $A_{t}$, is a shock to technology, which has a covariance stationary growth rate. Fixed costs are growing at the same rate as $z_{t}^{*}$, which captures the economy's balanced growth rate:

$$
z_{t}^{*}=A_{t} \Upsilon^{\frac{\alpha}{1-\alpha} t}, \Upsilon>1
$$

If fixed costs were not growing, then they would eventually become irrelevant. Notice that the growth rate of $z_{t}^{*}$, i.e. $\mu_{z, t}^{*} \equiv \Delta \log \left(z_{t}^{*}\right)$, exceeds that of $A_{t}$, i.e. $\mu_{A, t} \equiv \Delta \log \left(A_{t}\right)$ :

$$
\mu_{z, t}^{*}=\mu_{A, t}+[\alpha /(1-\alpha)] \log (\Upsilon)
$$

The additional source of growth in the economy is the result of the trend increase in the efficiency of investment, which translates into a decline in its relative price $\chi_{t}=\left(\zeta_{\Upsilon, t} \Upsilon^{t}\right)^{-1}$. This is in the spirit of Greenwood et al. (1997), who point out that technological improvements in the production of investment goods should determine a progressive decline in their relative price. The stochastic time series representation of the growth rate of the composite technology shock is:

$$
\mu_{z, t}^{*}=\left(1-\rho_{\mu_{z}^{*}}\right) \mu_{z}^{*}+\rho_{\mu_{z}^{*}} \mu_{z, t-1}^{*}+\sigma_{\mu_{z}^{*}}\left(\xi_{t}^{v o}\right) \varepsilon_{\mu_{z}^{*}, t}, \varepsilon_{\mu_{z}^{*}, t} \sim N(0,1)
$$

Following Calvo (1983), a fraction $1-\xi_{p}$, randomly chosen, of the intermediate good firms are permitted to reoptimize their price every period. Of the remaining firms, a (randomly selected) fraction $1-\iota_{p}$ must set $P_{i, t}=\Pi P_{i, t-1}$ and a fraction $\iota_{p}$ sets $P_{i, t}=\Pi_{t-1} P_{i, t-1}$, where $\Pi_{t} \equiv P_{t} / P_{t-1}$ is gross inflation. The $j^{t h}$ firm that has the opportunity to reoptimize its price does so to maximize the expected present discounted value of future profits:

$$
E_{t} \sum_{s=0}^{\infty}\left(\beta \xi_{p}\right)^{s}\left(\lambda_{t+s} / \lambda_{t}\right)\left[P_{j, t+s} \Pi_{t, t+s} Y_{j, t+s}-W_{t+s} L_{j, t+s}-P_{t+s} r_{t+s}^{k} K_{j, t+s}\right]
$$

subject to the demand function (1), where $\lambda_{t}$ is the marginal utility of nominal income for the representative household that owns the firm.

Market clearing and fiscal authority: The market clearing condition for this economy is $C_{t}+\left(\zeta_{\Upsilon, t} \Upsilon^{t}\right)^{-1} I_{t}+G_{t}=Y_{t}^{G}$, where $G_{t}$ denotes government expenditures and $Y_{t}^{G}$ is measured $G D P$, i.e., $Y_{t}^{G} \equiv Y_{t}-a\left(u_{t}\right) \Upsilon^{-t} \bar{K}_{t-1}$. The government issues short-term bonds and moves lump-sum taxes $T_{t}$ in order to finance government expenditure. Government 
expenditure follows an exogenous law of motion:

$$
\widehat{g}_{t}=\rho_{g} \widehat{g}_{t-1}+\sigma_{g}\left(\xi_{t}^{v o}\right) \varepsilon_{g, t}, \varepsilon_{g, t} \sim N(0,1)
$$

where $\widehat{g}_{t}=\log \left(g_{t} / g\right)$ and $g_{t} \equiv G_{t} / z_{t}^{*}$ is detrended government expenditure. In the steady state $G / Y^{G}=\eta_{G}$.

Monetary Policy: Conditional on a specific regime, captured by the hidden variable $\xi_{t}^{s p}$, the behavior of the monetary authority is described by:

$$
\frac{R_{t}}{R}=\left(\frac{R_{t-1}}{R}\right)^{\rho_{R}\left(\xi_{t}^{s p}\right)}\left[\left(\frac{\Pi_{t}}{\Pi}\right)^{\phi_{\pi}\left(\xi_{t}^{s p}\right)}\left(\frac{Y_{t}^{G} / Y_{t-1}^{G}}{e^{\mu_{z}^{*}}}\right)^{\phi_{y}\left(\xi_{t}^{s p}\right)}\right]^{1-\rho_{R}\left(\xi_{t}^{s p}\right)} e^{\sigma_{R}\left(\xi_{t}^{v o}\right) \epsilon_{R . t}}
$$

where $e^{\mu_{z}^{*}}$ is the steady-state gross growth rate of the economy. The central bank responds to deviations in inflation and output growth from their respective target levels, adjusting the monetary policy interest rate. Unanticipated deviations from the systematic component of the monetary policy rule are captured by $\epsilon_{R, t}$. The target for inflation is assumed to be constant over time. What changes is the strength with which the Fed tries to pursue its goals, not the goals themselves. This is in line with the idea that the Fed might find high inflation acceptable under some circumstances, perhaps in order to preserve output stability, but not desirable in itself. This seems in line with the reading of Burns' speeches that make clear that his worry was about the cost of a disinflation, but that he still regarded low inflation as the desirable goal of monetary policy. Furthermore, Liu et al. (2011) find that changes in the inflation target play little role in explaining macroeconomic volatility in a MS-DSGE model that allows for heteroskedastic shocks. ${ }^{4}$

Agents in the model know the probability of moving across regimes and they use this information when forming expectations. The probability of moving across regimes depends solely on the regime that is in place at time $t$. It would seem natural to make the transition probabilities endogenous, for example, depending on the level of inflation. However, two orders of problems arise in this context. First, solving the model becomes much more complicated and computationally intensive (Davig and Leeper (2006)). Second, this would require the estimation of threshold values. However, the number of regime switches is not likely to be high enough to pin down these thresholds.

\footnotetext{
${ }^{4}$ From a purely technical point of view, when allowing for both a MS Taylor rule and a drifting inflation target, it becomes difficult to distinguish a change in the target from a change in the Taylor rule parameters without bringing more information into the estimates (i.e., an observation variable for the target). Furthermore, if a change in the target is used to explain the behavior of the Fed in the '70s, counterfactual experiments become a bit less meaningful because they require an arbitrary choice for the target.
} 


\subsection{Solving and estimating the MS-DSGE model}

The technology process $A_{t}$ is assumed to have a unit root and the price of technology declines at the gross rate $\Upsilon$. Therefore, in the steady state, the economy grows at the gross rate $e^{\mu_{z, t}^{*}}=e^{\mu_{A, t}} \Upsilon^{\frac{\alpha}{1-\alpha}}$. In order to induce stationarity, consumption, output, and government expenditure are detrended using $z_{t}^{*}=A_{t} \Upsilon^{\frac{\alpha}{1-\alpha} t}$. Investment and capital are rescaled using $z_{t}^{*} \Upsilon^{t}$, to control for the progressive decline in the relative price of investment. Once the model is rewritten in terms of detrended variables, the nonstochastic steady state can be computed. Note that in this model, the steady state is not affected by the MS Taylor rule (see Schorfheide (2005) and Liu et al. (2011)). Conditional on a particular regime, the model can be linearized. The system of linearized equations can be found in the online appendix.

If we collect all the structural parameters and the stochastic volatilities in two vectors $\theta^{s p}$ and $\theta^{v o}$ and define the DSGE state vector $S_{t}$ containing all the variables, we can rewrite the system of linearized equations in a compact form:

$$
\Gamma_{0}\left(\xi_{t}^{s p}, \theta^{s p}\right) S_{t}=\Gamma_{1}\left(\xi_{t}^{s p}, \theta^{s p}\right) S_{t-1}+\Psi Q\left(\xi_{t}^{v o}, \theta^{v o}\right) \varepsilon_{t}+\Pi \eta_{t}
$$

where the vector $\eta_{t}$ contains the expectation errors, the vector $\varepsilon_{t}$ contains all the shocks described above, and $Q\left(\xi_{t}^{v o}, \theta^{v o}\right)=\operatorname{diag}\left(\theta^{v o}\right)$ is a diagonal matrix collecting the volatilities of the shocks conditional on the regime that is in place at time $t$.

A model in this form in which there are no regime changes could be easily solved using the solution method for linear rational expectations models described in Sims (2002). In the current context, computations become more complicated because the model is quasi-linear, i.e., it is linear only conditioning on $\xi_{t}^{s p}$. The solution algorithm employed in this paper is based on the work of Farmer et al. (2010). The authors show that it is possible to reduce the task of finding a minimal state variable solution to that of computing the roots of a quadratic polynomial in several variables. ${ }^{5}$ When a solution exists, it can be characterized as a regime-switching vector autoregression, of the kind studied by Hamilton (1989), Chib (1996), and Sims and Zha (2006):

$$
S_{t}=T\left(\xi_{t}^{s p}, \theta^{s p}, H^{s p}\right) S_{t-1}+R\left(\xi_{t}^{s p}, \theta^{s p}, H^{s p}\right) Q\left(\xi_{t}^{v o}, \theta^{v o}\right) \varepsilon_{t}
$$

It is worth emphasizing that the law of motion of the DSGE states depends on the structural parameters $\left(\theta^{s p}\right)$, the regime in place $\left(\xi_{t}^{s p}\right)$, and the probability of moving across

\footnotetext{
${ }^{5}$ The solution method proposed by Farmer et al. (2010) does not rule out the possibility of indeterminacy. For this reason, I have also experimented with a solution method proposed by Cho (2010) that provides conditions for determinacy focusing on models that are stable when solved forward. When both converge, the two methods return the same solution.
} 
regimes $\left(H^{s p}\right)$. This means that what happens under regime $i$ does not only depend on the structural parameters describing that particular regime but also on what agents expect is going to happen under alternative regimes and on how likely it is that a regime change will occur in the future (see also Davig and Leeper (2007)). In other words, agents' beliefs matter for the law of motion governing the economy. The regime for the stochastic volatilities $\xi_{t}^{v o}$ enters through the matrix $Q\left(\xi_{t}^{v o}, \theta^{v o}\right)$, but it does not affect the matrices $T(\cdot)$ and $R(\cdot)$. These matrices would be affected if higher order approximations were used. Using perturbation methods, Foerster et al. (2010) take important steps in this direction. However, at this stage, the algorithm they propose is not fast enough to be used in an estimation algorithm. I regard this as a promising area for future research, given the recent evidence on the impact of uncertainty on agents' behavior (Bloom (2009), Fernández-Villaverde et al. (2011)).

In principle, agents in the model might form expectations using a transition matrix $H^{m}$ that differs from the objective transition matrix that is observed ex-post by the econometrician $\left(H^{s p}\right)$. For example, it might take some time for agents to learn about this transition matrix or agents might be more or less pessimistic about the future conduct of monetary policy. However, in this paper the benchmark model assumes $H^{s p}=H^{m}$, i.e., agents share the same information set as the econometrician, because more information would be needed to pin down the two matrices separately. This assumption has the important implication that the estimated transition matrix $H^{s p}$ will reflect both the frequency of regime changes and agents' beliefs around these changes.

The law of motion (4) can be combined with a system of observation equations:

$$
X_{t}=D\left(\theta^{s p}\right)+Z S_{t}+U v_{t}, v_{t} \sim N(0, I)
$$

where $X_{t}$ contains the observables, $D$ is a matrix of constants, $Z$ maps the MS law of motion (4) into the observables, and $v_{t}$ is a vector containing observation errors. ${ }^{6}$

For a DSGE model with fixed parameters the likelihood can be easily evaluated using the Kalman filter and then combined with a prior distribution for the parameters. When dealing with a MS-DSGE model, the standard Kalman filter cannot be applied. Please refer to appendix A for a description of the Bayesian algorithm used in this paper.

\footnotetext{
${ }^{6}$ Observation errors are included for inflation and price of investment only. As in Justiniano and Primiceri (2009), they are important for inflation but virtually zero for the price of investment.
} 


\begin{tabular}{|c|c|c|c|c|c|c|c|}
\hline & \multicolumn{4}{|c|}{ Posterior } & \multicolumn{3}{|c|}{ Prior } \\
\hline Parameter & Mode & Mean & $5 \%$ & $95 \%$ & & Mean & Std Dev \\
\hline$\phi_{\pi}\left(\xi^{s p}=1\right)$ & 2.3914 & 2.3235 & 1.8927 & 2.7364 & $N$ & 1.8 & 0.4 \\
\hline$\phi_{\pi}\left(\xi^{s p}=2\right)$ & 0.9477 & 1.1188 & 0.8085 & 1.4946 & $G$ & 1 & 0.4 \\
\hline$\phi_{y}\left(\xi^{s p}=1\right)$ & 0.0559 & 0.1920 & 0.0853 & 0.3315 & $G$ & 0.25 & 0.15 \\
\hline$\phi_{y}\left(\xi^{s p}=2\right)$ & 0.3127 & 0.3196 & 0.1171 & 0.5753 & $G$ & 0.25 & 0.15 \\
\hline$\rho_{R}\left(\xi^{s p}=1\right)$ & 0.6070 & 0.6679 & 0.5266 & 0.7812 & $B$ & 0.6 & 0.2 \\
\hline$\rho_{R}\left(\xi^{s p}=2\right)$ & 0.6679 & 0.7775 & 0.6359 & 0.8790 & $B$ & 0.6 & 0.2 \\
\hline$H_{11}^{s p}$ & 0.9861 & 0.9534 & 0.8746 & 0.9925 & Dir & .9091 & 0.0830 \\
\hline$H_{22}^{s p}$ & 0.9345 & 0.9045 & 0.8286 & 0.9644 & Dir & .9091 & 0.0830 \\
\hline$S^{\prime \prime}$ & 8.9976 & 9.6458 & 4.8038 & 15.4526 & $G$ & 4 & 2 \\
\hline$\sigma_{A}$ & 0.6689 & 0.6744 & 0.4071 & 1.0765 & $G$ & 2 & 1 \\
\hline$\xi_{p}$ & 0.9004 & 0.9059 & 0.8807 & 0.9279 & $B$ & 0.5 & 0.1 \\
\hline$\iota_{p}$ & 0.9515 & 0.9147 & 0.8225 & 0.9773 & $B$ & 0.5 & 0.2 \\
\hline$\rho_{g}$ & 0.9894 & 0.9882 & 0.9818 & 0.9935 & $B$ & 0.6 & 0.2 \\
\hline$\rho_{\zeta_{I}}$ & 0.6084 & 0.6715 & 0.5490 & 0.7990 & $B$ & 0.6 & 0.2 \\
\hline$\rho_{\zeta_{C}}$ & 0.2552 & 0.2391 & 0.1249 & 0.3713 & $B$ & 0.6 & 0.2 \\
\hline$\rho_{\zeta_{\Upsilon}}$ & 0.9969 & 0.9960 & 0.9919 & 0.9990 & $B$ & 0.6 & 0.2 \\
\hline$\rho_{\mu_{z}^{*}}$ & 0.3700 & 0.3816 & 0.1469 & 0.5915 & $B$ & 0.4 & 0.2 \\
\hline $100 \mu_{z}^{*}$ & 0.3944 & 0.3963 & 0.3801 & 0.4125 & $N$ & 0.4 & 0.01 \\
\hline $100 \log (\Pi)$ & 0.6544 & 0.6359 & 0.5565 & 0.7079 & $N$ & 0.5 & 0.05 \\
\hline $100\left(\beta^{-1}-1\right)$ & 0.1673 & 0.1811 & 0.1291 & 0.2384 & $G$ & 0.25 & 0.05 \\
\hline$\Phi$ & 0.9046 & 0.9299 & 0.9106 & 0.9466 & $B$ & 0.5 & 0.1 \\
\hline$\lambda_{f}-1$ & 0.1293 & 0.1276 & 0.047 & 0.2089 & $N$ & 0.15 & 0.05 \\
\hline $100 \log (\Upsilon)$ & 0.3756 & 0.3734 & 0.3583 & 0.3880 & $N$ & 0.29 & 0.01 \\
\hline$\sigma_{L}$ & 2.4693 & 3.0513 & 2.0677 & 4.3423 & $G$ & 2 & 0.75 \\
\hline $100 \sigma_{R}\left(\xi^{v o}=1\right)$ & 0.0555 & 0.0993 & 0.0703 & 0.1357 & $I G$ & 0.2 & 0.2 \\
\hline $100 \sigma_{R}\left(\xi^{v o}=2\right)$ & 0.2938 & 0.2886 & 0.2307 & 0.3717 & $I G$ & 0.2 & 0.2 \\
\hline $100 \sigma_{\zeta_{I}}\left(\xi^{v o}=1\right)$ & 2.6726 & 2.7877 & 1.9675 & 4.0730 & $I G$ & 2 & 2 \\
\hline $100 \sigma_{\zeta_{I}}\left(\xi^{v o}=2\right)$ & 4.5090 & 5.0603 & 3.7876 & 7.2410 & $I G$ & 2 & 2 \\
\hline $100 \sigma_{\zeta_{C}}\left(\xi^{v o}=1\right)$ & 3.5283 & 4.5325 & 3.3703 & 5.9266 & $I G$ & 1 & 1 \\
\hline $100 \sigma_{\zeta_{C}}\left(\xi^{v o}=2\right)$ & 4.2344 & 6.5269 & 4.7523 & 8.7190 & $I G$ & 1 & 1 \\
\hline $100 \sigma_{\zeta_{\Upsilon}}\left(\xi^{v o}=1\right)$ & 0.4501 & 0.4495 & 0.3912 & 0.5071 & $I G$ & 0.5 & 0.5 \\
\hline $100 \sigma_{\zeta_{\Upsilon}}\left(\xi^{v o}=2\right)$ & 0.6809 & 0.6597 & 0.5629 & 0.7889 & $I G$ & 0.5 & 0.5 \\
\hline $100 \sigma_{\mu_{z}^{*}}\left(\xi^{v o}=1\right)$ & 1.0161 & 0.8697 & 0.6264 & 1.1768 & $I G$ & 2 & 2 \\
\hline $100 \sigma_{\mu_{z}^{*}}\left(\xi^{v o}=2\right)$ & 1.7481 & 1.9061 & 1.3246 & 2.6498 & $I G$ & 2 & 2 \\
\hline $100 \sigma_{g}\left(\xi^{v o}=1\right)$ & 2.2007 & 1.9385 & 1.5564 & 2.3158 & $I G$ & 1 & 2 \\
\hline $100 \sigma_{g}\left(\xi^{v o}=2\right)$ & 3.4119 & 3.5434 & 2.9455 & 4.3220 & $I G$ & 1 & 2 \\
\hline$H_{11}^{v o}$ & 0.9693 & 0.9278 & 0.8714 & 0.9701 & Dir & .9048 & 0.0626 \\
\hline$H_{22}^{v o}$ & 0.9457 & 0.8955 & 0.8107 & 0.9590 & Dir & .9048 & 0.0626 \\
\hline $100 \sigma_{\pi}$ & 0.3257 & 0.3121 & 0.2794 & 0.3465 & $I G$ & 0.05 & 0.1 \\
\hline $100 \sigma_{p i}$ & 0.0463 & 0.0508 & 0.0372 & 0.0704 & $I G$ & 0.05 & 0.01 \\
\hline
\end{tabular}

Table 1: Modes, Mean, 90\% error bands, and prior distributions of the parameters of the Markov-switching DSGE model. 


\section{Results}

The benchmark model allows for a total of four regimes: two for the structural parameters and two for the stochastic volatilities. The overall volatility of the economy is pinned down by the interaction between the central bank's behavior and the volatility of the structural shocks, implying a total of four different covariance matrices for the variance of the data (see Subsection 3.5). This is why two regimes for the stochastic volatilities suffice to characterize changes in the volatility of the macroeconomy. Furthermore, Liu et al. (2011) show that in this class of models, more regimes for the stochastic volatilities are not favored by the data.

As observables, I use six series of U.S. quarterly data: real GDP per capita (y), annualized quarterly inflation $(\pi)$, the federal funds rate (FFR), real consumption per capita $(c)$, investment in terms of consumption units $(i)$, and price of investment $(p i)$. All the variables, except for inflation and the FFR, enter as log-differences (i.e., net growth rates). The sample spans 1954:Q3 to 2009:Q2. The results shown below are based on five chains of 920,000 Gibbs sampling replications each. For each chain, the first 20,000 draws are discarded as burn-in and of the remaining 900,000 draws, one of every 1,000 draws is retained. ${ }^{7}$

\subsection{Parameter estimates and regime probabilities}

Table 1 reports priors, modes, means, and 90\% error bands for the DSGE parameters and the diagonal elements of the transition matrices. The priors for the parameters that do not move across regimes are in line with previous results in the literature and are relatively loose, except for the steady-state growth rates of the economy and the relative price of investment. The priors on the stochastic volatilities are symmetric across regimes and are quite loose. As for the parameters of the Taylor rule, the priors for the response to output growth and the degree of autocorrelation are symmetric across regimes, while I have chosen asymmetric priors for the responses to inflation. ${ }^{8}$ This is meant to reflect the a priori belief that the inflationary stance of the Federal Reserve has changed over time. However, it is important to notice that the priors are very loose, implying a substantial degree of overlap, and that under Regime 2, values above 1 receive around $45 \%$ of the a priori probability. Finally, I choose the following normalizations that imply truncations of the joint prior: 1) For the stochastic volatilities, Regime 2 is the high volatility regime and the volatilities of the monetary policy,

\footnotetext{
${ }^{7}$ See appendices $\mathrm{B}$ and $\mathrm{C}$ for details about the construction of the data set and evidence about convergence based on the Brooks-Gelman-Rubin potential reduction scale factor. Since the chain is started around the posterior mode, relatively few draws are discarded.

${ }^{8}$ Asymmetric priors facilitate the implementation of the normalization always necessary when working with Markov-switching models $\left(\phi_{\pi}\left(\xi^{s p}=1\right)>\phi_{\pi}\left(\xi^{s p}=2\right)\right.$ in this case). The online appendix shows that the posterior mode estimates are not affected when using symmetric priors.
} 

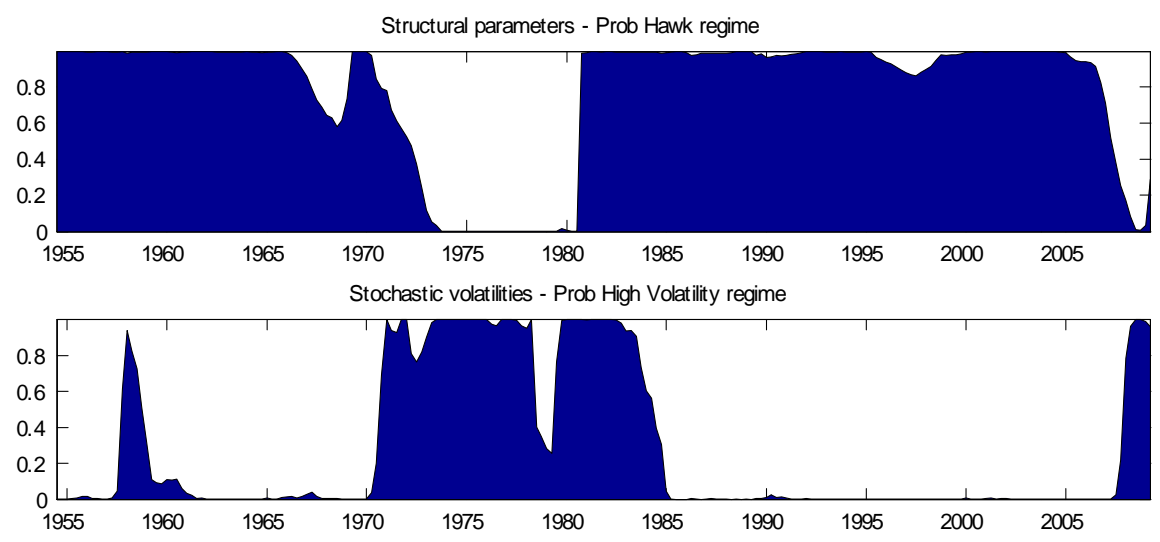

Figure 2: MS-DSGE model, posterior mode estimates: Top panel, probability of Regime 1 for the structural parameters, the Hawk regime; lower panel, probability of Regime 2 for the stochastic volatilities, high volatility regime.

investment, and government expenditure shocks are higher under this regime, 2) For the Taylor rule parameters, Regime 1 is the "more active" regime, i.e., the response to inflation is higher under this regime. Note that this is only a matter of labeling, as the likelihood would be unchanged if the regimes were labeled in the opposite way. Finally, I fix $\alpha=.3$, $\delta=.025$, and the steady-state ratio between government expenditure and GDP to $\eta_{G}=.22$.

Concerning the parameters of the Taylor rule, under Regime $1\left(\xi_{t}^{s p}=1\right)$ the FFR reacts strongly to deviations of inflation from its target, while output growth does not seem to be a major concern. The opposite occurs under Regime 2. The degree of interest rate smoothing turns out to be similar across regimes. For obvious reasons, I shall refer to Regime 1 as the Hawk regime, while Regime 2 will be the Dove regime. At the posterior mode, if the two regimes were taken in isolation and embedded in a fixed coefficient DSGE model, only the former would imply determinacy. However, the persistence of the Dove regime is significantly smaller than that of the Hawk regime, implying that the dynamics under the Dove regime are influenced by the behavior of the Fed under the Hawk regime. The point estimate of the inflation target is 0.6544 , implying an annual value around $2.62 \%$. As for the other parameters, the value for the degree of indexation is relatively high, implying that the process for inflation is quite persistent. The estimated Calvo price stickiness parameter $\xi_{p}$ is around 0.90, which is in line with the values reported by Smets and Wouters (2007) and Justiniano and Primiceri (2008).

Figure 2 shows the (smoothed) probabilities assigned to $\xi_{t}^{s p}=1$ (top panel) and $\xi_{t}^{v o}=2$ (lower panel). Confronting these probabilities with narrative accounts of monetary policy history is a way to understand whether the results are reasonable. To facilitate the interpretation of the results, the three panels of Figure 3 display the filtered and actual series 

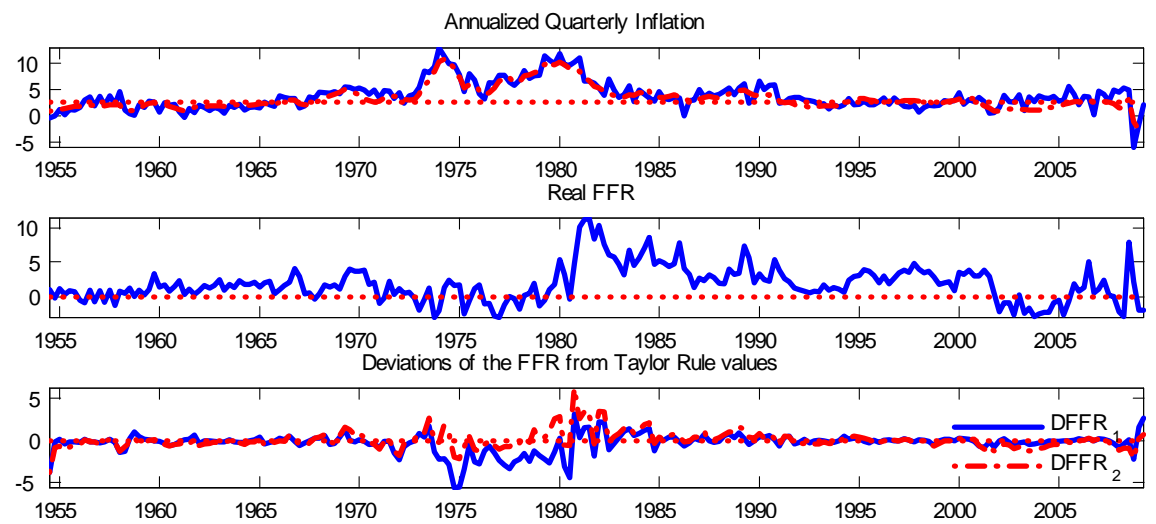

Figure 3: The top panel reports annualized quarterly inflation (observed and filtered) and the inflation target. The second panel contains a proxy for the annualized real FFR, computed as $F F R_{t}-\pi_{t+1}$. The last panel displays the differences between the observed FFR and the ones implied by the two alternative Taylor rules (i.e., $\left.D F F R_{1}=F F R-F F \widehat{R\left(\xi_{t}^{s p}\right.}=1\right)$ ).

of quarterly annualized inflation, the pattern of realized real interest rates (computed as $\left.R_{t}-\pi_{t+1}\right)$, and the difference between the observed FFR and the interest rate that would be implied by the two Taylor rules. During a period characterized by high (low) inflation, a large negative (positive) difference between the observed interest rate and its predicted value under Regime 1 implies that the Fed is not responding strongly enough to inflation deviations.

Monetary policy turns out to be active during the early years of the sample, from 1955 to the mid-60s. Romer and Romer (2002) provide narrative evidence in favor of the idea that the Fed's stance toward inflation during this period was substantially similar to that of the '90s. They also show that a Taylor rule estimated over the sample 1952:1-1958:4 would imply determinacy. Furthermore, after the presidential election of 1960, Richard Nixon blamed his defeat on excessively tight monetary policy implemented by the Fed. At that time, Fed Chairman Martin had a clear goal in mind, that the Fed was "to take away the punch bowl just as the party gets going," i.e., to raise interest rates in response to an overheated economy.

Toward the end of the '60s, the probability of the Dove regime increases for a couple of years, in conjunction with the first significant and persistent increase in inflation. However, the probability of the Hawk regime moves quickly back to one as inflation seems under control.

In February 1970, Arthur F. Burns was appointed Chairman by Richard Nixon. Burns is often thought to be responsible for the high and variable inflation that prevailed during the '70s. It is commonly accepted that on several occasions he had to succumb to the requests of the White House. In fact, the estimates show that for almost the entire duration of his 
mandate, the Fed followed a passive Taylor rule. During these years, the Hawk regime would have required a much higher monetary policy interest rate.

This long period of passive monetary policy ended around the second half of 1980, shortly after Paul Volcker took office in August 1979. Volcker was appointed with the precise goal of ending the high inflation. The jump in the probability of the Hawk regime confirms the widespread belief that he delivered on his commitment. However, the timing of the regime change does not perfectly coincide with the appointment of the new Chairman. This can be rationalized by observing the behavior of the endogenous variables. In 1980 the FFR, after an initial sharp increase, shows a large drop followed by a further increase in inflation. The third panel of Figure 3 shows how the initial increase in the FFR reduces the distance between the observed FFR and the one implied by the hawkish Taylor rule. However, this change does not last, and at the beginning of 1980, the model still prefers the Dove regime and interprets the spike in the FFR as a large shock. Interestingly, this result formalizes the story proposed by Goodfriend and King (2005), who argue that "the start of a deliberate disinflation dates to late 1980" and that the initial increase in the FFR did not represent a substantial departure from the way monetary policy was conducted in the '70s: A timid attempt at controlling inflation, resulting in even higher inflation.

The path for the realized real interest rate of Figure 3 highlights the sharp contrast between the two periods. During the Burns chairmanship, real interest rates were negative or very close to zero, whereas, under Volcker's chairmanship, they increased to unprecedented heights. During those years, inflation began to decline and the economy experienced a deep recession, while the Fed was still keeping the FFR high.

For the remainder of the sample until the appointment of Bernanke in January 2005 the Hawk regime has been the rule. It is worth emphasizing that the probability of the Hawk regime is basically one during the period 2001-2005. Several commentators have argued that during those years, the FFR had been too low for too long. These results show that the remarkably low FFR can be justified in light of a distinct risk of deflation.

As emphasized by Sims and Zha (2006) and Cogley and Sargent (2006), it is essential to account for the stochastic volatility of exogenous shocks when trying to identify shifts in monetary policy. In fact, it turns out that a change in the volatilities of the structural shocks contributes to the broad picture. A high volatility regime, Regime 2, was in place for a large part of the period that goes from the early '70s to the mid-80s, with a break between the two oil crises. This result is quite informative because 1984 is regarded as a turning point in U.S. economic history. There are two alternative ways to interpret this finding. On the one hand, even if a regime change occurred well before 1984, perhaps the conquest of American inflation was actually determined by a break in the uncertainty characterizing 
the macroeconomy. On the other hand, this same break might have occurred in response to the renewed commitment of the Federal Reserve to a low and stable inflation. Both interpretations suggest that the uncertainty characterizing the economy and the behavior of the Fed are likely to be interdependent. The Great Inflation was characterized by high volatilities and loose monetary policy, and in a similar vein, the Great Moderation emerged after a reduction in the volatilities of the structural shocks and a drastic change in the conduct of monetary policy.

This prolonged period of active monetary policy and low uncertainty came to an end with the recent crisis. The probability of the high volatility regime quickly increases in 2008, when the financial crisis accelerated. This change in volatility is preceded by a switch in the conduct of monetary policy, which moves from the Hawk to the Dove regime. Of course, during 2008 the Fed started conducting unconventional monetary policy, and this should be taken into consideration in interpreting the results. However, it is important to point out that monetary policy started drifting well before 2008, with the probability of the Hawk regime declining starting in 2005. Transcripts from the meetings of the Federal Open Market Committee (FOMC) show that in 2006, the Fed did not have a clear understanding of the consequences of the housing market crash, so these changes cannot be interpreted in light of the imminent crisis. At that time, many members of the FOMC shared the optimistic view that the end of the housing market bubble would have a few consequences for the real economy. The Fed Chairman, Ben Bernanke, initially agreed (March 2006), but he later changed his position, warning that problems in the housing market could spread to the rest of the economy. However, at the time of the December 2006 meeting, this was not the dominant opinion among FOMC members and financial practitioners. The model attributes part of the large drop in real activity and inflation to this lack of responsiveness by the Fed.

To summarize, these results strongly support the idea that the appointment of Volcker marked a change in the Fed's inflation stance compared to the '70s. At the same time, they question the widespread belief that U.S. monetary policy history can be described in terms of a permanent and one-time-only regime change: pre- and post-Volcker.

\subsection{Impulse response analysis}

In order to illustrate the differences in dynamics across the two regimes, the left-hand side of Figure 4 reports impulse responses to an investment-specific shock, while the right-hand side displays the impulse responses to a technology shock. In each case, the first column reports the median for the Hawk (solid line) and Dove regime, while the second column contains the median and $68 \%$ error bands for the difference between the two responses. As elsewhere in 

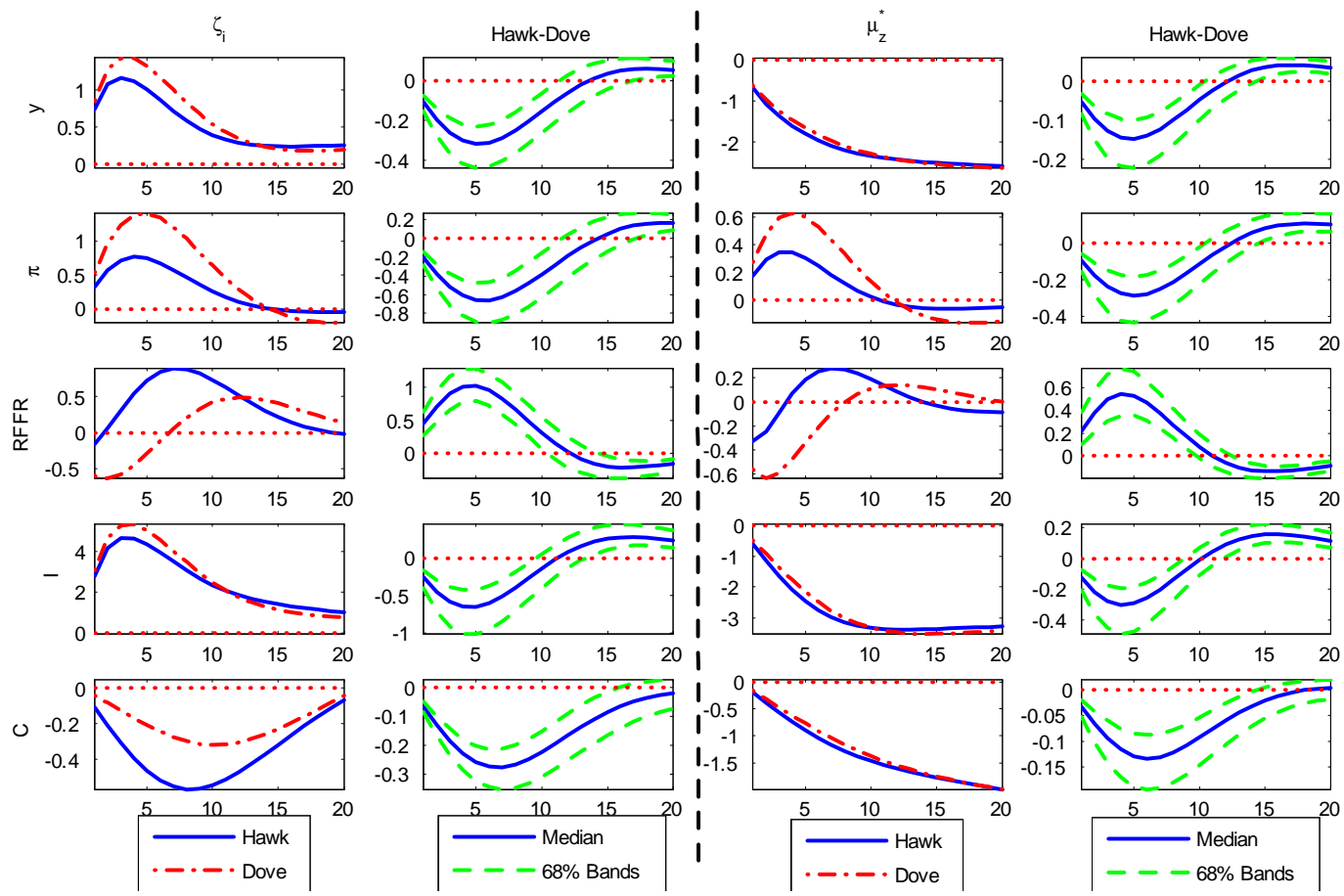

Figure 4: The figure displays impulse responses for output, inflation, real FFR, investment, and consumption and it is divided into two parts. The left-hand side reports impulse responses to an investment technology shock, whereas the right-hand side displays the impulse responses to a technology shock. In each case, the first column reports the median for the Hawk (solid) and Dove (dashed) regime, and the second column contains the median and $68 \%$ error bands for the difference between the two responses.

the literature, these two shocks capture a large fraction of output and inflation volatilities. Impulse response functions are computed conditional on one regime being in place for the entire time horizon. Nevertheless, the paths of the variables still differ from the ones that would be obtained by solving a fixed coefficient DSGE model because agents' expectations reflect the possibility of a regime change.

An investment shock moves inflation, investment, and output upward, but it determines a decline in consumption. Across the two regimes the responses are quite different in magnitude. The decline in consumption is substantially smaller under the Dove regime, at the cost of a larger increase in inflation. It is instructive to isolate the behavior of the real FFR, reported in the third row of Figure 4: Under the Hawk regime, after an initial short decline due to the autoregressive component of the Taylor rule, it becomes large and positive, whereas under the Dove regime it is large and negative for almost two years, after which it becomes positive.

Following a slowdown in the growth rate of technology, all real variables move down, but inflation increases. The difference in the behavior of inflation is quite pronounced. To 
capture the differences in the real variables, it might be useful to focus on the last column of Figure 4. The smaller increase in inflation under the Hawk regime is associated with statistically significant and prolonged reductions in all the real variables. The behavior of the real FFR is once again quite different across the two regimes.

Three considerations are in order. First, the gains in terms of lower inflation achieved under the Hawk regime are relatively large in response to an investment shock but are somehow less pronounced following an adverse technology shock. Second, negative technology shocks imply a large toll on society because of the change in the stochastic trend, so the cost of stable and low inflation might be perceived as particularly expensive when these shocks dominate. Third, no matter the nature of the shock that hits the economy, the cost in terms of lower output and consumption implied by the Hawk regime are large and persistent.

\subsection{Counterfactual analysis}

When working with models that allow for regime changes it is interesting to simulate what would have happened had regime changes not occurred, or had they occurred at different points in time, or had they occurred when they otherwise did not. This kind of analysis is even more meaningful in the context of the MS-DSGE model employed in this paper. First, like a standard DSGE model, the MS-DSGE model can be re-solved for alternative policy rules to address the effects of fundamental changes in the policy regime. The entire law of motion changes in a way that is consistent with the new assumptions around the behavior of the monetary policy authority. Furthermore, the solution depends on the transition matrix used by agents when forming expectations and on the nature of the alternative regimes. Therefore, we can investigate what would have happened if agents' beliefs about the probability of moving across regimes had been different. This has important implications for counterfactual simulations in which a regime is assumed to have been in place throughout the sample because the expectation mechanism and the law of motion are consistent with the fact that no other regime would have been observed.

Last but not least, new counterfactual simulations can be explored: beliefs counterfactuals. In these counterfactuals agents are endowed with specific beliefs about alternative regimes. These regimes might never occur, but they could still have important effects on the dynamics of the variables through the expectation mechanism. This particular kind of counterfactual analysis is not possible in the context of a Markov-switching or time-varying VAR in which there is no explicit role for agents' expectations and forward-looking variables. 

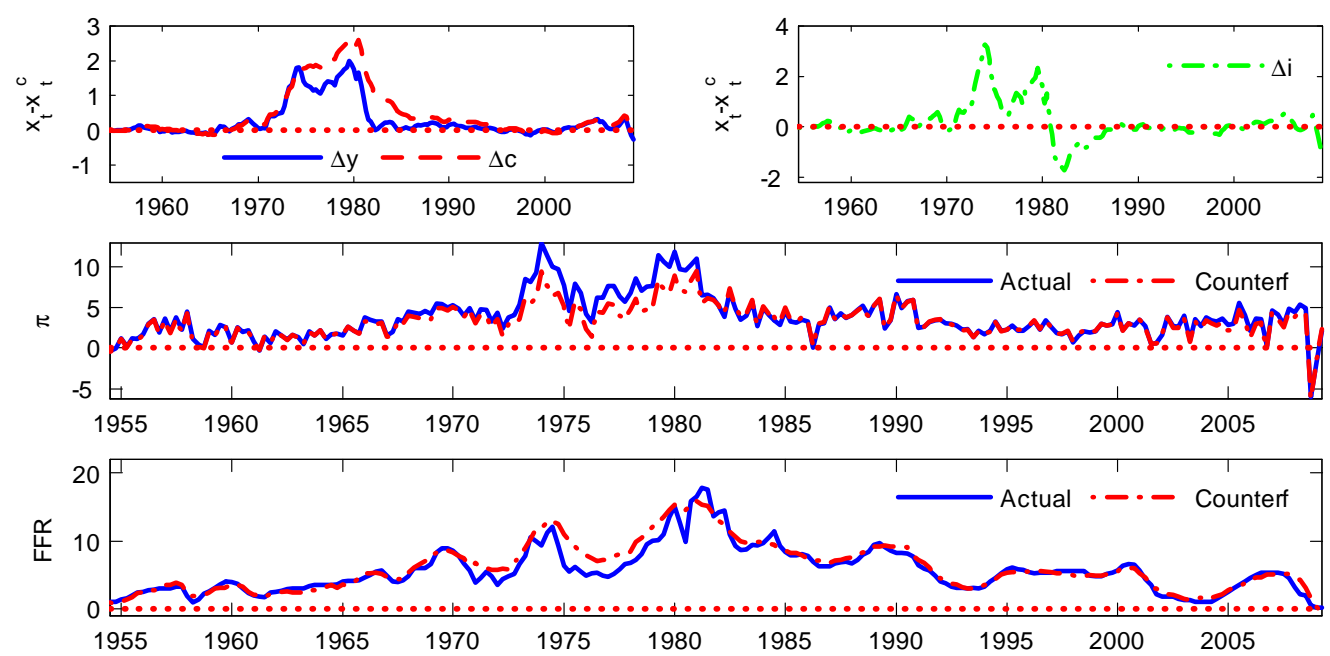

Figure 5: Counterfactual simulation based on the Hawk regime being in place over the entire sample. The first two panels report the difference between actual and counterfactual series for output (solid line), consumption, and investment. The last two panels contain actual (solid line) and counterfactual series for inflation and the FFR.

\subsubsection{A fixed Hawk regime}

The most natural question we can try to answer is how things would have changed if the Fed had always followed the hawkish Taylor rule. Therefore, in the first counterfactual, the Hawk regime is imposed over the entire sample. To make the results consistent with this assumption, the model is solved assuming that agents regard the Hawk regime as the only one that is possible. In other words, for each draw from the posterior, I solve a fixed coefficient version of the model in which the behavior of the Fed is described by the Hawk regime parameters. The parameters of the model that do not enter the Taylor rule and the non-monetary policy disturbances are left unchanged, while the monetary policy shocks are set to zero.

Figure 5 shows the results: The first two panels in the first row contain output, consumption, and investment losses implied by the counterfactual simulation, whereas the second and third rows contain the actual (solid line) and counterfactual (dashed line) series for inflation and the FFR. ${ }^{9}$ It is apparent that the Fed would not have been able to completely avoid the rise in inflation but would have managed to partially contain it, at the cost of a substantial and prolonged loss in terms of output. Fernández-Villaverde et al. (2010) reach a similar conclusion. This is reassuring given the methodological differences between the two papers.

\footnotetext{
${ }^{9}$ For clarity, the figures report only the median of the counterfactual series. Similar graphs with error bands are available upon request. Output, consumption, and investment losses are computed as the difference between the logs of the correspective actual and counterfactual series; therefore, the number reported on the vertical axis can be interpreted as percentage losses (if the number is positive) or gains.
} 

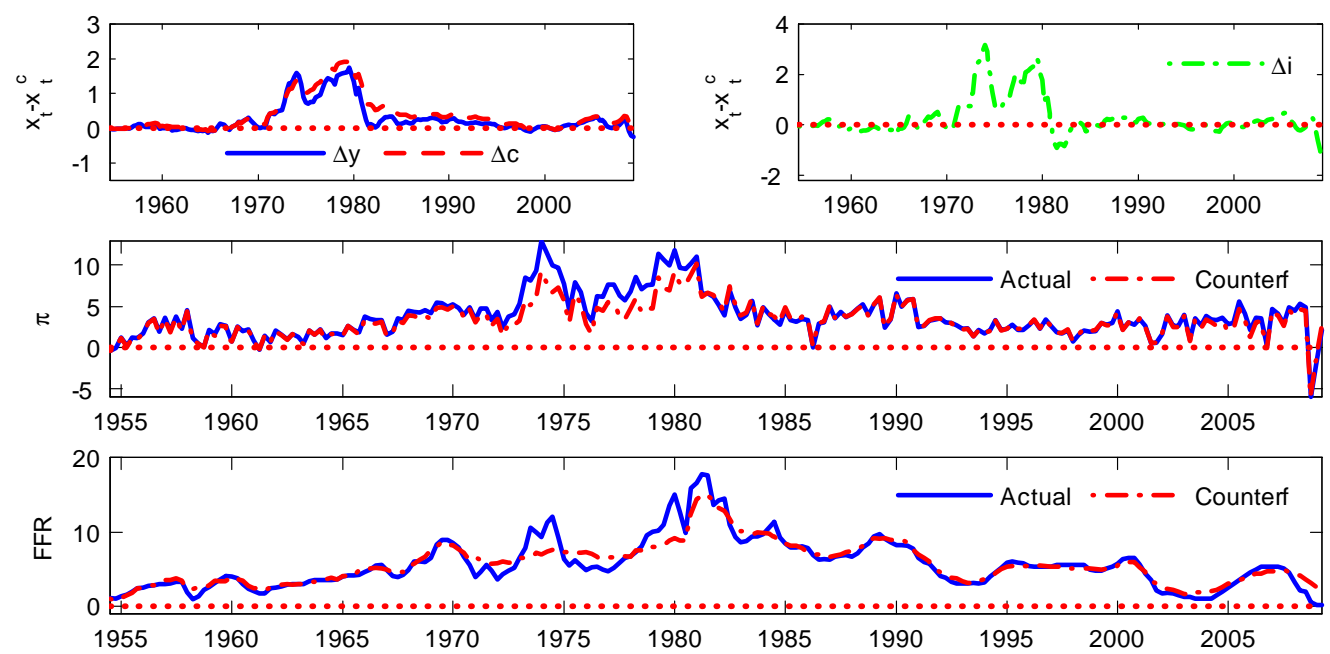

Figure 6: Counterfactual simulation based on having a very hawkish regime, the Eagle regime, that receives a very high probability whenever the Dove regime is in place, even if it never occurred in the sample. The first two panels report the difference between actual and counterfactual series for output (solid line), consumption, and investment. The last two panels contain actual (solid line) and counterfactual series for inflation and the FFR.

The losses in terms of lower consumption would also have been very large, with a peak of $3 \%$ around the appointment of Volcker. A small fraction of the investment loss would have been reabsorbed during the early ' 80 s because the Volcker disinflation would have been milder, with a path for the FFR below the one observed during the early '80s. On the other hand, the losses in consumption would have kept accumulating until the early 90s and would never have been reabsorbed.

Focusing on the end of the sample, it is possible to detect gains in output, consumption, and investment. This suggests that if the Hawk regime had been in place, the consequences of the financial crisis would have been mitigated because agents would have perceived the Fed as more active. Interestingly, under the counterfactual simulation the FFR is initially higher because a sequence of negative monetary policy shocks has been removed and the Fed is in part reacting to an upward trend in inflation. This suggests an interesting interpretation regarding why the Fed was unable to prevent a large fall in output: Agents might have perceived the measures implemented by the Federal Reserve during the recent crisis as temporary, instead of being part of a more systematic rule. Of course, such beliefs might have been justified in light of the possibility of hitting the zero lower bound. And in fact this is what happens in the very last period, when the FFR becomes lower than in the data and negative. Of course, this represents a limit to the implementability of the Hawk regime. However, the following counterfactual simulations suggest that even in this case an exit strategy exists. 


\subsubsection{An Eagle behind the scenes}

From what has been shown so far, it seems that, in the '70s, no reduction in inflation could have been achieved without a substantial output loss. At the same time, the Fed's ability to prevent the recent drop in real activity might have been limited by the possibility of hitting the zero lower bound. However, the role of agents' beliefs surrounding alternative monetary policy regimes has not yet been explored. The simple and intriguing exercise conducted in this section asks what would have happened if, during the high inflation of the '70s, agents had put a relatively large probability on the appointment of a very conservative Chairman, willing to fight inflation without any concern for the state of the real economy. I shall label this hypothetical third scenario the Eagle regime, because it is even more hawkish than the Hawk regime. The Eagle regime differs from the Hawk regime in terms of the response to inflation, which is assumed to be twice as large, and to output, which is half as large. Note that this implies a strong response to deviations of inflation from the target and it might have beneficial effects even when facing sudden drops in real activity and inflation as in the recent crisis.

In this first belief counterfactual, the Eagle regime never occurs over the sample, but I assume that when agents observe the Dove regime, they regard the Eagle regime as a likely alternative scenario and they put a relatively large probability on its occurrence. To that end, the probability of staying in the Dove regime is reduced by $30 \%$ and the probability of moving directly to the Hawk regime is four times smaller than the probability of having to go through the Eagle regime first. The probability of staying in the Eagle regime is equal to the persistence of the Hawk regime. From the Eagle regime the economy can move only to the Hawk regime. These assumptions imply an interesting interpretation of the Eagle regime: It is a regime that occurs with high probability after a period of dovish monetary policy in order to restore credibility and return to the ordinary active regime.

Figure 6 contains the results. The behavior of inflation looks somewhat similar to the one obtained in the previous section. However, there are some notable differences in the output loss and the FFR. The former turns out to be smaller and the latter is remarkably lower over the second half of the '70s, the years during which the Dove/Eagle regime prevails. Consumption also shows a more favorable behavior compared to the Hawk counterfactual. It turns out that the threat of the Eagle regime is enough to deliver very similar results in terms of low inflation, with a substantial reduction in the output loss. Note that all the results are driven by the high probability that agents assign to the Eagle regime. The FFR is low because inflation is relatively low and the Dove regime is in place. What keeps inflation down is the fact that agents anticipate the possibility of a drastic change in the conduct of monetary policy. 

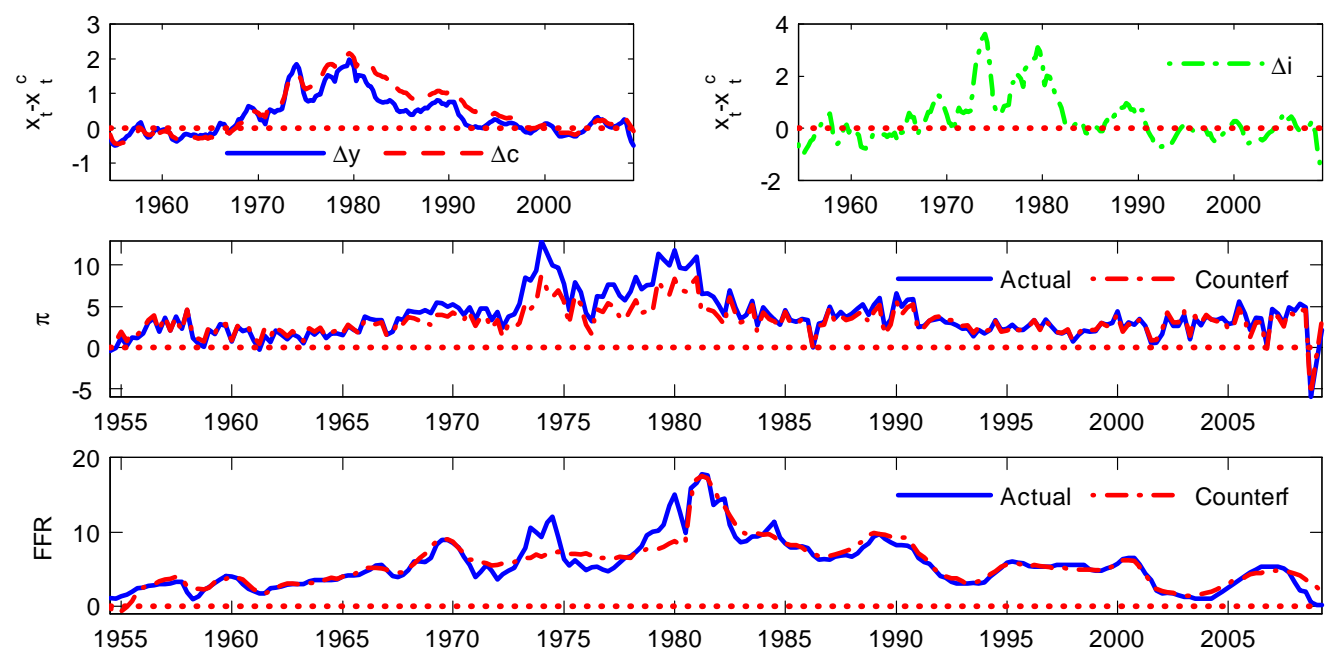

Figure 7: Counterfactual simulation in which the Hawk regime is replaced with the Eagle regime and the persistence of the Dove regime is decreased by $30 \%$. The left column reports actual and counterfactual series. The first two panels report the difference between actual and counterfactual series for output (solid line), consumption, and investment. The last two panels contain actual (solid line) and counterfactual series for inflation and the FFR.

The results for more recent years are also interesting. The counterfactual simulation implies a gain in terms of output that is obtained with an interest rate that is visibly higher than in the data. Even in this case, agents' beliefs are at work, with agents expecting the Federeal Reserve to be very active in pushing inflation back to its target level in the near future. Notice that compared to the Hawk counterfactual, here the problem of implementability is less relevant, as the Dove regime is still in place and the recovery is not sustained by the current actions of the Federal Reserve but by its expected future behavior.

The goal of this exercise is not to propose a new way to conduct monetary policy: Maintain dovish policy today while trying to persuade the public that the Fed will be extremely active in the future. This kind of strategy clearly presents a problem of credibility. However, two lessons can be learned from this experiment. First, it is quite possible that the problem in the '70s was not that the Fed was not reacting strongly enough to inflation, but that there was a lack of confidence about the possibility of a substantial change in the conduct of monetary policy. Second, this exercise suggests that the alternative scenarios that agents have in mind are at least as important as the regime that is in place. The recent increase in transparency implemented by the Federal Reserve could be explained in light of this result. 


\subsubsection{An Eagle on stage}

In the second beliefs counterfactual, the Hawk regime is replaced with the Eagle regime described in the previous section. Even in this case, the transition matrix is twisted: The probability of staying in the active regime is kept unchanged, while the persistence of the Dove regime is lower by $30 \%$. Therefore, agents have in mind a transition matrix that implies only short deviations from this very hawkish regime.

Figure 7 contains the results. Note that inflation and output would have been lower during the '70s, without substantial increases in the FFR. Even in this case, the result is driven largely by the expectation mechanism. Then, in the early '80s the Eagle regime becomes effective and we observe a jump in the FFR and a further reduction in inflation. Quite interestingly, during the early '80s, the path for the FFR is hardly distinguishable from the actual one, suggesting that the Eagle regime does a good job in replicating the behavior of the Federal Reserve during the early years of Volcker's chairmanship.

These outcomes differ from the case in which the Hawk regime is assumed to be in place throughout the sample. If the Hawk regime had been replaced by the Eagle regime, inflation would have been lower and the output and consumption losses more spread out over the years. However, it is not clear if the final cost in terms of output and consumption would have been different: The output and consumption losses are positive in the early '80s, but they are clearly smaller in the second half of the '70s, when the Dove regime is in place. Finally, in correspondence with the recent recession, output would have been visibly different, with the gain coming mostly from a smaller drop in investment. As was the case in the previous counterfactual, this does not require a large drop in the FFR that is visibly larger than the actual series. Agents expect the Federal Reserve to revert to the very active regime as soon as more normal conditions are restored. This is enough to partially mitigate the drop in real activity.

This last counterfactual simulation points to an important conclusion: If a central bank were able to commit to a flexible inflation targeting, in which severe shocks are temporarily accommodated and followed by a strong commitment to bring the economy back to the steady state, then it would be possible to achieve low and stable inflation with lower output costs. In other words, the effective sacrifice ratio would be smaller. Similarly, during extraordinary events such as the recent crisis, a flexible rule of this sort would allow the Federal Reserve to better deal with the constraints imposed on its actions. Admittedly, this kind of policy is not readily practicable. Among other things, the duration of the deviation matters a lot. When inflationary shocks are large and persistent, as they were in the '70s, if the central bank decides to implement a dovish monetary policy, agents are likely to be discouraged about the possibility of moving back to an active regime. In this context, there is no clear way to 


\begin{tabular}{cccccccc} 
& $C F S R^{y}$ & $C F S R^{c}$ & $\Delta \% S S D_{y}$ & $\Delta \% S S D_{\pi^{A}}$ & $\Delta y_{\text {end }}$ & $\Delta i_{\text {end }}$ & $\Delta c_{\text {end }}$ \\
\hline \hline Hawk & 57.36 & 74.04 & -3.08 & -53.28 & 0.26 & 0.97 & -0.03 \\
& $(43.99,78.17)$ & $(59.62,98.76)$ & $(-6.27,-0.66)$ & $(-64.04,-33.31)$ & $(-0.05,0.69)$ & $(0.23,1.99)$ & $(-0.30,0.30)$ \\
EbeS & 51.62 & 59.36 & -4.73 & -49.53 & 0.25 & 1.08 & -0.11 \\
& $(39.98,67.87)$ & $(48.81,73.25)$ & $(-8.01,-2.45)$ & $(-57.62,-38.59)$ & $(-0.04,0.67)$ & $(0.33,2.15)$ & $(-0.33,0.17)$ \\
EonS & 49.89 & 56.49 & -7.11 & -70.30 & 0.51 & 1.59 & 0.08 \\
& $(39.27,64.37)$ & $(46.80,67.72)$ & $(-10.35,-4.56)$ & $(-75.26,-63.59)$ & $(0.21,0.86)$ & $(0.90,2.58)$ & $(-0.19,0.35)$ \\
\hline \hline
\end{tabular}

Table 2: For each counterfactual simulation, the first two columns report the median and the $68 \%$ error bands for the counterfactual sacrifice ratios as defined in formula (6) in terms of output and consumption losses. The third and fourth columns contain the percentage changes of squared deviations from target for inflation and output growth with respect to what is observed in the data over the period 1967:Q2-1980:Q2. Finally, the last three columns report the end of sample gains for GDP, investment, and consumption.

persuade agents that a regime change is around the corner. At the same time, uncertainty about the nature of the recent crisis might have limited the Fed's ability to manage agents' expectations.

\subsubsection{Quantifying gains and losses}

Table 2 quantifies gains and losses arising from the different counterfactuals. The first column contains the counterfactual sacrifice ratio, a tentative measure of the cost of bringing inflation down during the Great Inflation of the '70s. This is defined as:

$$
C F S R_{T_{0}, T_{1}}^{x}=100 *\left[\sum_{t=T_{0}}^{T_{1}}\left(x_{t}-\widehat{x}_{t}\right)\right] /\left[\sum_{t=T_{0}}^{T_{1}}\left(\pi_{t}-\widehat{\pi}_{t}\right)\right]
$$

where the numerator and the denominator are the cumulative difference between the realized and counterfactual values for a measure of real activity (consumption or output) and realized and counterfactual inflation, respectively. Intuitively, the larger this number, the larger the cost of lowering inflation. Notice that simply imposing the Hawk regime would have implied the largest sacrifice ratio, whereas the Eagle on stage (EonS) and Eagle behind the scenes (EbeS) counterfactuals deliver similar and more favorable values. The difference is remarkably large when looking at the cost in terms of consumption, but it is also statistically and economically significant when looking at the losses in terms of output. ${ }^{10}$

However, it might be more enlightening to look at the relative performance of the different counterfactuals over the entire sample. The third and fourth columns contain the percentage change in the sum of squared deviations of output growth and inflation from their respective targets (with respect to the data) under the three counterfactuals. The Eagle on stage counterfactual implies smaller losses both in terms of output and inflation compared to

\footnotetext{
${ }^{10}$ In fact, the output losses would be even larger if government expenditure were modeled as a fraction of GDP.
} 
the Hawk counterfactual and the Eagle behind the scenes. The Eagle behind the scenes is preferred to the Hawk counterfactual in terms of output stability, but it implies slightly larger deviations in inflation from the target. When compared to the actual losses, all counterfactuals imply substantial gains in inflation (up to $70.3 \%$ with the Eagle on stage counterfactual) and relatively small gains in terms of output stability. Desirability of these different outcomes depends on the sources of fluctuations and on the relative weights given to output and inflation stability, whereas attainability is linked to the Fed's ability to commit. With regard to this, Bernanke (2003) points out that U.S. monetary policy is conducted according to constrained discretion: The Fed can accommodate temporary shocks because, starting with the Volcker disinflation, it has built credibility for its commitment to keeping inflation low and stable. In the context of this paper, this is the same as saying that the Eagle on stage counterfactual is a more credible way to conduct monetary policy after the events of the early ' 80 s.

Finally, the last three columns focus on the recent crisis, reporting end-of-the-sample gains for output, investment, and consumption. Notice that the Eagle on stage counterfactual is the most successful in determining an increase in output. This is very encouraging, given that this counterfactual scenario does not require any immediate change in the conduct of monetary policy and it is therefore easier to implement when facing the risk of hitting the zero lower bound. Finally, the table highlights that these gains come mostly from a reduction in the drop of investment, while consumption is substantially unaffected.

\subsubsection{Endogenous and Markov regime changes}

Before proceeding, some considerations about the relation between a MS-DSGE model and a model with endogenous regime changes are in order, since it is quite possible that in reality regime switches are endogenous. For example, it could be that whenever inflation is high, a conservative Chairman is appointed. If the benchmark model considered in this paper were fitted to data generated by such an economy, the estimated transition matrix would reflect not only the observed frequency of regime changes but also the interaction between the state of the economy and agents' beliefs. This implies that under some circumstances, the MS-DSGE model could be a good proxy for the underlying law of motion. Suppose, for example, that in our hypothetical economy a dovish regime happens to prevail over a period of high inflation and that the structure of the model is perfectly known. Agents in the true economy, observing inflation approaching the threshold that triggers a regime change, would attach a large probability to the appointment of a hawkish Chairman. In the estimated MS-DSGE model, this would be reflected in a relatively small persistence of the Dove regime. Furthermore, if the level of inflation were homogeneous over the period of 

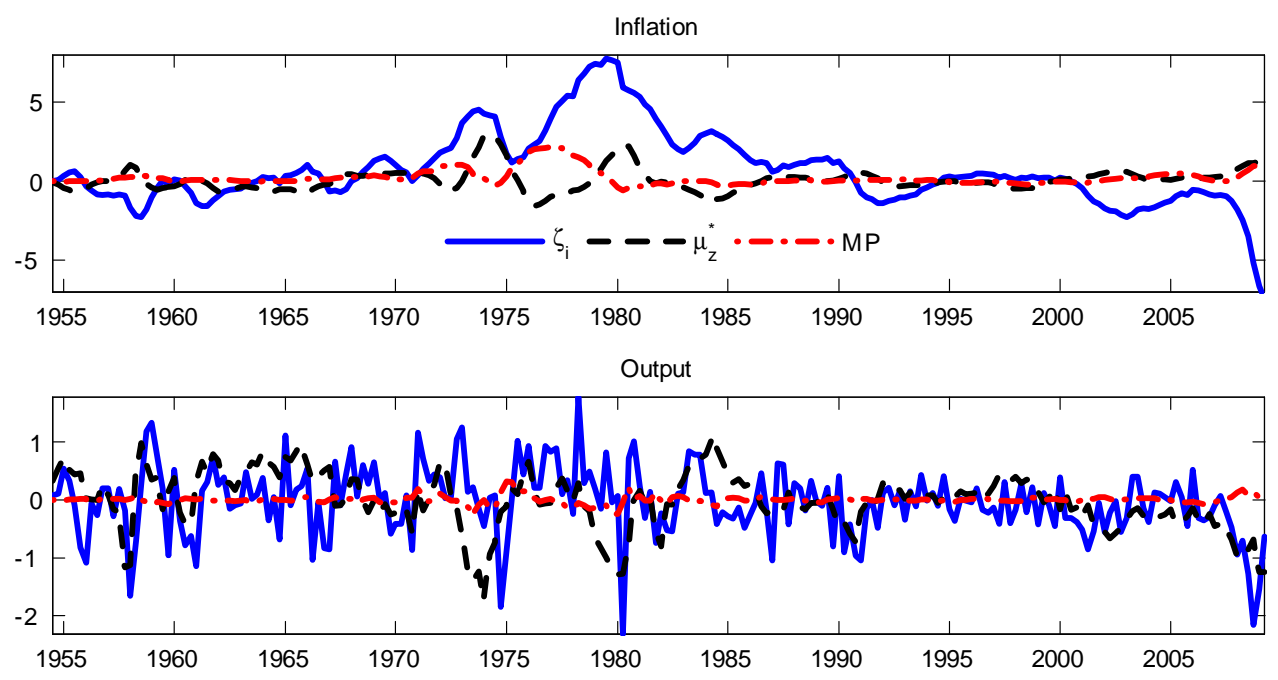

Figure 8: The figure shows the cumulative contribution of investment-specific, technology, and monetary policy shocks in determining changes in inflation and output growth.

interest, the probability of a regime change would be almost constant even in the true model, making the exogeneity assumption of the MS-DSGE model less restrictive. Therefore, while the predictions for events far in the future would differ, the reduced-form properties of the MS-DSGE model could be a good approximation of reality because agents' beliefs about the short-run evolution of monetary policy would be reflected in the transition matrix.

Following this line of thought, and keeping in mind that the two models are very different in spirit, the beliefs counterfactuals that have been considered here could be interpreted as a modeling device to investigate how the economy would have behaved if in the '70s agents, observing very high inflation, had perceived a regime change to a very aggressive regime as particularly likely. In the context of a MS-DSGE model this boils down to twisting the transition matrix and/or changing the behavior of the Fed under alternative regimes.

\subsection{Dynamic shock decomposition}

In this section, I conduct a shock decomposition for the evolution of inflation and output growth. I report results for three shocks that are of particular interest: investment-specific, technology, and monetary policy. I first consider the actual decomposition, and then I show how things would have changed under the three alternative counterfactuals.

Figure 8 reports the cumulative contributions of the three shocks to movements in inflation and output growth. Summing across all the shock contributions at each point in time returns the actual changes in the two series with respect to the starting point, 1954:Q3. It is quite evident that the investment specific shock contributes substantially to the run-up of in- 

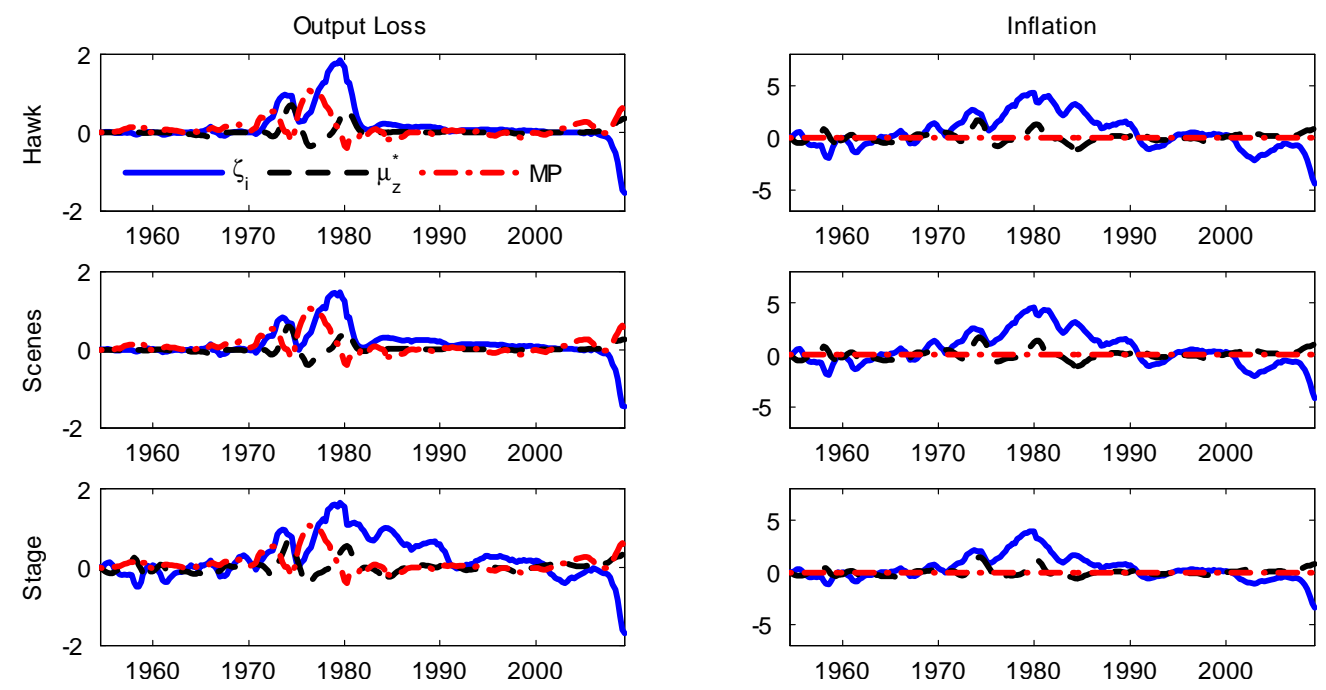

Figure 9: The figure analyzes the counterfactual contribution of the investment-specific, technology, and monetary policy shocks to output losses and inflation.

flation during the '70s. Its cumulative contribution is very close to $8 \%$ by the end of the '70s. At the same time, it also plays an important role in explaining the sudden drop in inflation and the slowdown in output growth that occurred during the recent crisis. Justiniano et al. (2011) also find that the recent drop in investment and output is in large part explained by an adverse investment-specific shock, and they document a strong commovement between the shock and the credit spread. Therefore, the model captures the recent financial crisis through a deterioration in the efficiency of investment. This seems like a plausible proxy in the absence of a fully modeled financial sector.

The technology shock is important in capturing the two oil crises, characterized by episodes of stagflation, with output growth dropping and inflation rising. Furthermore, the shock helps to explain the contemporaneous drop in investment and consumption that occurred in correspondence of the recent crisis. Finally, monetary policy shocks play a nonnegliglible role during the ' $70 \mathrm{~s}$, with a peak that is as high as $2 \%$. This implies that during the period between the two oil crises, the FFR was too high, even under the assumption that the Dove regime was in place. Finally, a series of monetary policy shocks partially mitigate the drop in inflation and output growth during the late years of the sample.

Figure 9 analyzes the impact of the same shocks under the counterfactual scenarios. For each counterfactual simulation, the left column contains the median of the shock contributions to the output loss, while the right column reports the contribution to the evolution of inflation (the scale of the graph is kept unchanged with respect to Figure 8). It is not surprising that during the '70s a large output loss is associated with the investment-specific shock 
across all counterfactual simulations. The largest value is associated with the Hawk counterfactual, under which the output loss would have been almost $2 \%$. However, relatively large losses are also associated with the monetary policy and technology shocks. The second column shows that under these counterfactual scenarios, the impact of the investment-specific shock on inflation is greatly mitigated. Concerning the first Hawk counterfactual, it is easy to interpret the results in light of the impulse responses reported in Subsection 3.2: Every time an investment-specific shock hits the economy, its impact on inflation is cut in half when the Hawk regime is in place. Under the maintained counterfactual assumption that agents regard the Hawk regime as the only possible one, this effect is even stronger. Under the two beliefs counterfactuals, a similar reduction in the impact of the shock on inflation is obtained even if the regime in place in the '70s is kept unchanged.

As for the recent crisis, it has been shown before that the Federal Reserve could have partially reduced the drop in inflation and growth. These graphs highlight that these gains would have been largely generated by the interaction between the counterfactual policies and the investment-specific shock. In light of the link between the marginal efficiency of investment and the credit spread documented by Justiniano et al. (2011), this appears to be an interesting result that should receive attention in future research, perhaps using a model that allows for unconventional monetary policy.

\subsection{Actual and counterfactual volatilities}

In this section, I compute the volatilities of the macroeconomic variables for all possible combinations of the monetary policy and volatility regimes. It is well known that high inflation is often associated with high volatility. This was surely the case in the '70s. This exercise provides a way to understand what would have changed if the Hawk regime had been in place during those years. Furthermore, I compute counterfactual volatilities based on the Eagle on stage counterfactual described in Subsection 3.3.3.

The block in the upper-left corner of Table 3 plots the model-implied standard deviations for five of the six macroeconomic variables under the Dove-High Volatility regime combination. ${ }^{11}$ This is treated as the benchmark case. Moving to the right, the table reports the percentage change due to a regime change: The second, third, and fourth blocks assume, respectively, a change in both regimes, a change in the volatility regime only, and a change in monetary policy only. In the lower half of the table, I have reported the gains from the Eagle on stage counterfactuals across different regime combinations. All the gains are expressed

\footnotetext{
${ }^{11}$ I use the following notation: Do Dove, Ha Hawk, Do ${ }^{E}$ counterfactual Dove, Ea Eagle, Hv High Volatility, $L v$ Low Volatility. I excluded the price of investment, given that its variance does not depend on the Fed's behavior.
} 


\begin{tabular}{c|cccc} 
Actual & Std Do,Hv & $\% \Delta \mathbf{H a}, \mathbf{L v}$ & $\% \Delta$ Do,Lv & $\% \Delta \mathbf{H a}, \mathrm{Hv}$ \\
\hline \hline$d y$ & $\mathbf{1 . 5 9}$ & -51.42 & -47.73 & -5.52 \\
& $(1.46,1.77)$ & $(-56.30,-45.96)$ & $(-52.59,-42.30)$ & $(-8.60,-2.81)$ \\
$\pi$ & $\mathbf{4 . 5 8}$ & -61.93 & -41.58 & -44.21 \\
& $(3.96,5.38)$ & $(-67.20,-56.64)$ & $(-46.45,-36.32)$ & $(-52.10,-36.73)$ \\
$F F R$ & $\mathbf{3 . 9 6}$ & -39.01 & -47.32 & 15.29 \\
& $(3.47,4.58)$ & $(-48.19,-30.38)$ & $(-52.25,-42.02)$ & $(0.37,25.05)$ \\
$d i$ & $\mathbf{4 . 0 2}$ & -50.86 & -45.49 & -8.90 \\
& $(3.67,4.51)$ & $(-56.68,-44.88)$ & $(-51.61,-39.05)$ & $(-13.26,-5.88)$ \\
$d c$ & $\mathbf{0 . 7 6}$ & -40.88 & -42.98 & 4.99 \\
& $(0.69,0.86)$ & $(-47.20,-33.66)$ & $(-49.07,-36.05)$ & $(2.97,7.18)$ \\
\hline Count. & $0 \Delta \mathbf{D o}, \mathrm{Hv}$ & $\% \Delta \mathbf{E a}, \mathbf{L v}$ & $\% \Delta \mathbf{D o} \mathbf{D o}^{E}, \mathbf{L v}$ & $\% \Delta \mathbf{E a}, \mathrm{Hv}$ \\
\hline \multirow{2}{*}{$d y$} & -7.78 & -53.24 & -52.86 & -7.98 \\
& $(-11.32,-4.99)$ & $(-58.14,-47.80)$ & $(-57.60,-47.55)$ & $(-12.05,-4.42)$ \\
$\pi$ & -48.21 & -69.45 & -63.75 & -63.07 \\
\multirow{2}{*}{$F F R$} & $(-54.38,-42.13)$ & $(-73.87,-64.91)$ & $(-68.37,-59.08)$ & $(-68.03,-58.02)$ \\
& -37.56 & -39.05 & -70.79 & 14.33 \\
$d i$ & $(-47.97,-26.61)$ & $(-48.83,-29.54)$ & $(-76.16,-65.12)$ & $(-1.98,27.58)$ \\
& -12.05 & -53.97 & -52.75 & -14.17 \\
$d c$ & $(-17.10,-8.61)$ & $(-59.67,-47.91)$ & $(-58.44,-46.71)$ & $(-19.86,-10.08)$ \\
& 2.49 & -39.61 & -42.12 & 8.36 \\
\hline \hline
\end{tabular}

Table 3: The panel in the upper-left corner reports the model-implied standard deviations under the DoveHigh Volatility regime combination. This is treated as the benchmark case. Moving to the right, the table reports the percentage change in the volatilities due to a regime change. The lower section of the table reports the percentage changes (w.r.t. the benchmark case) caused by replacing the Hawk regime with the Eagle regime and decreasing the persistence of the Dove regime (Eagle on stage counterfactual). Bold letters are used to denote the regime that is changing w.r.t. the benchmark case.

in percentage points with respect to the benchmark regime combination.

Four results can be highlighted. First, for the volatility of inflation a change in monetary policy is more important than a change in the volatility of the structural shocks, whereas the opposite is true for all other variables. This result is in line with Justiniano and Primiceri (2008), who find that a more hawkish monetary policy would have made a difference for the volatility of inflation in the pre-Volcker era. Second, a more hawkish monetary policy implies an overall reduction in the volatility of the macroeconomy, with the important exception of consumption growth, for which we observe an increase in volatility. Third, the Eagle on stage counterfactual delivers gains in the volatility of inflation that are in line with the ones implied by a change in monetary policy (compare $H a, H v$ with $D_{o}^{E}, H v$ ). Furthermore, the increase in the volatility of consumption is less pronounced and the decline in the volatility of the FFR is substantial. Finally, the gains from the beliefs counterfactual are larger when the economy is under the Dove regime, even if what is changing is the Fed's behavior under the hawkish regime (see, for example, the additional gains from moving from $H a, H v$ to $E a, H v$, compared to moving from $D o, L v$ to $\left.D o^{E}, L v\right)$. These last two results confirm the important role played by agents' beliefs in this class of models. 


\begin{tabular}{ccccc} 
Model & $p=0.1$ & $p=0.3$ & $p=0.5$ & $p=0.7$ \\
\hline \hline MS T.R.+heter. & $4,394.6$ & $4,392.1$ & $4,390.2$ & $4,387.6$ \\
Heter. only & $4,375.4$ & $4,376.5$ & $4,376.9$ & $4,377.2$ \\
\hline \hline
\end{tabular}

Table 4: Marginal data density (log) for different values of $\mathrm{p}$, the fraction of draws used in the numerical approximation.

\section{Model Comparison}

The final step consists of assessing whether the data favor a model that allows for changes in the behavior of the Federal Reserve. Bayesian model comparison is based on the posterior odds ratio:

$$
\frac{P\left(M_{i} \mid Y_{T}\right)}{P\left(M_{j} \mid Y_{T}\right)}=\frac{P\left(Y_{T} \mid M_{i}\right)}{P\left(Y_{T} \mid M_{j}\right)} \frac{P\left(M_{i}\right)}{P\left(M_{j}\right)}
$$

where $M_{i}$ and $M_{j}$ are two competing models. The second term on the RHS is the prior odds ratio, i.e., the relative probability assigned to the two models before observing the data, while the first term is the Bayes factor, the ratio of marginal likelihoods. Assuming that all models are regarded as equally likely a priori, the Bayes factor is all we need to conduct model comparison. The marginal data density is computed according to the method described in Sims et al. (2008) to deal with the fact that when allowing for time-varying parameters the posterior tends to be non-Gaussian.

Table 4 reports the log marginal data density for different values of $p$, the fraction of draws used to compute the marginal data density. I compare the benchmark model, with a model that allows for heteroskedasticity but not for changes in monetary policy. Bayesian model comparison automatically penalizes models with a larger number of parameters. Nevertheless, the benchmark specification turns out to be preferred. In this dimension, the paper differs from previous contributions that find little evidence of parameter instability beyond that implied by heteroskedasticity (e.g., Sims and Zha (2006) and Liu et al. (2011)).

\section{Conclusions}

Many economists like to think about U.S. monetary policy history in terms of pre- and postVolcker. The underlying idea is that since the Volcker disinflation, the Fed has acquired a better understanding of how to manage the economy and provide a stable and reliable anchor for agents' expectations. Using a Markov-switching model in which agents form expectations taking into account the possibility of regime changes, this paper has shown that the Fed has moved back and forth between a Hawk and a Dove regime. The appointment of Volcker came with a substantial change in the conduct of monetary policy, and the '70s were surely 
dominated by the Dove regime, but this is not enough to explain the rise in inflation that occurred in those years. If the Hawk regime had been in place over the entire sample, inflation would have been lower but with significant losses in terms of output and consumption.

However, the appointment of Volcker might have been important for its impact on agents' expectations. Through a new kind of counterfactual simulation, I have shown that if agents had put a large probability on the appointment of a very conservative Chairman, inflation would have been significantly lower. Moreover, the cost in terms of output and consumption would have been reduced compared to the case in which the Hawk regime is assumed to be in place over the entire sample. Therefore, it seems that the main problem in the '70s might have been a lack of confidence in the possibility of quickly moving back to an active regime.

Beliefs counterfactuals also provide interesting insights about the recent recession. The model captures the drop in inflation and real activity at the end of 2008 resulting from an adverse shock to the efficiency of investment combined with the Dove regime. If during that period agents had anticipated an exceptionally active monetary policy in the near future, the consequences of the adverse shock would have been reduced without a substantial change in the FFR, mitigating the concerns about hitting the zero lower bound.

Even if with the Volcker disinflation the U.S. did not enter an absorbing state, there is some hope that events like the Great Inflation will not occur again: not because the Fed is likely to behave differently on impact, but because agents have now seen what follows a prolonged period of loose monetary policy. Obviously, this is an optimistic view. First, it is not clear to what extent agents learn from the past. More important, the probabilities that agents attach to the different regimes are likely to depend on the persistence of the shocks. Policymakers should avoid trying to accommodate those shocks that are likely to persist for a long time because this would determine a change in agents' beliefs. These considerations seem particularly relevant in light of the recent economic turmoil. In the past three years, the Federal Reserve has dealt with a pervasive and severe financial crisis. This led to substantial deviations from common monetary policy practice and a massive quantity of liquidity has been injected into the market. In light of the results of this paper, the Fed's ability to deal effectively with the post-crisis exit strategy will depend on the alternative scenarios that agents have in mind. 


\section{References}

Altig, D., Christiano, L., Eichenbaum, M. and Linde, J.: 2011, Firm-Specific Capital, Nominal Rigidities and the Business Cycle, Review of Economic Dynamics 14(2), 225-247.

Benati, L. and Surico, P.: 2009, VAR Analysis and the Great Moderation, American Economic Review 99(4), 1636-52.

Bernanke, B.: 2003, Constrained Discretion and Monetary Policy, Remarks before Money Marketeers of New York University.

Bernanke, B. S. and Mihov, I.: 1998, Measuring Monetary Policy, Quarterly Journal of Economics 113(3), 862-902.

Bloom, N.: 2009, The Impact of Uncertainty Shocks, Econometrica 77, 623-685.

Boivin, J. and Giannoni, M.: 2006, Has Monetary Policy Become More Effective?, Review of Economics and Statistics 88(3).

Calvo, G.: 1983, Staggered Prices in a Utility-Maximization Framework, Journal of Monetary Economics 12, 983-998.

Canova, F. and Gambetti, L.: 2004, On the Time Variations of US Monetary Policy: Who is right?, Money Macro and Finance (MMF) Research Group Conference 2004 96, Money Macro and Finance Research Group. available at http://ideas.repec.org/p/mmf/mmfc04/96.html.

Carter, C. and Kohn, P.: 1994, On Gibbs Sampling for State Space Models, Biometrika 81, 541-553.

Chib, S.: 1996, Calculating Posterior Distributions and Model Estimates in Markov Mixture Models, Journal of Econometrics 75, 79-97.

Cho, S.: 2010, Forward Method for Markov-Switching Rational Expectations Models, working paper.

Christiano, L., Eichenbaum, M. and Evans, C.: 2005, Nominal Rigidities and the Dynamic Effects of a Shock to Monetary Policy, Journal of Political Economy 113, 1-45.

Clarida, R., Gali, J. and Gertler, M.: 2000, Monetary Policy Rules and Macroeconomic Stability: Evidence and Some Theory, Quarterly Journal of Economics 115, 147-180.

Cogley, T. and Sargent, T. J.: 2006, Drifts and Volatilities: Monetary Policies and Outcomes in the Post WWII U.S., Review of Economic Dynamics 8, 262-302.

Davig, T. and Doh, T.: 2008, Monetary Policy Regime Shifts and Inflation Persistence, Federal Reserve Bank of Kansas City working paper.

Davig, T. and Leeper, E. M.: 2006, Endogenous Monetary Policy Regime Change, Indiana University working paper.

Davig, T. and Leeper, E. M.: 2007, Generalizing the Taylor Principle, American Economic 
Review 97(3), 607-635.

Farmer, R. E. A., Waggoner, D. and Zha, T.: 2010, Minimal State Variable Solutions to Markov-Switching Rational Expectations Models, Federal Reserve Bank of Atlanta, mimeo.

Fernández-Villaverde, J. and Rubio-Ramírez, J. F.: 2007, How Structural are Structural Parameters?, 2007 NBER Macroeconomics Annual .

Fernández-Villaverde, J., Rubio-Ramírez, J. F. and Guerrón-Quintana, P.: 2010, Fortune or

Virtue: Time-variant Volatilities versus Parameter Drifting in U.S. Data, Duke University working paper.

Fernández-Villaverde, J., Rubio-Ramírez, J. F., Guerrón-Quintana, P. and Uribe, M.: 2011, Risk Matters. The Real Effects of Volatility Shocks, American Economic Review 101(3), 2530-2561.

Fisher, J. D. M.: 2006, The Dynamic Effect of Neutral and Investment-Specific Technology Shocks, Journal of Political Economy 114(3), 413-51.

Foerster, A., Rubio-Ramírez, J. F., Waggoner, D. and Zha, T.: 2010, Perturbation Methods for Markov-Switching Models, working paper.

Goodfriend, M. and King, R.: 2005, The Incredible Volcker Disinflation, Journal of Monetary Economics 52(5), 981-1015.

Greenwood, J., Hercowitz, Z. and Krusell, P.: 1997, Long-Run Implications of InvestmentSpecific Technological Change, American Economic Review 87, 342-362.

Hamilton, J. D.: 1989, A New Approach to the Economic Analysis of Nonstationary Time Series and the Business Cycle, Econometrica 57, 357-384.

Justiniano, A. and Primiceri, G.: 2008, The Time Varying Volatility of Macroeconomic Fluctuations, American Economic Review 98(3), 604-41.

Justiniano, A. and Primiceri, G.: 2009, Potential and Natural Output, Northwestern University, mimeo.

Justiniano, A., Primiceri, G. and Tambalotti, A.: 2011, Investment Shocks and the Relative Price of Investment, Review of Economic Dynamics 14(1), 101-121.

Kim, C.-J. and Nelson, C. R.: 1999, State-Space Models with Regime Switching, MIT Press, Cambridge, Massachusetts.

Kim, C.-J. and Nelson, C. R.: 2004, Estimation of a Forward-Looking Monetary Policy Rule: A Time-Varying Parameter Model Using Ex-Post Data, Journal of Monetary Economics 53(8), 1949-1966.

Laforte, J.-P.: 2005, DSGE Models and Heteroskedasticity: A Markov-Switching Approach, Board of Governors of the Federal Reserve System, mimeo.

Leeper, E. M.: 1991, Equilibria Under Active and Passive Monetary and Fiscal Policies, 
Journal of Monetary Economics 27, 129-147.

Leeper, E. M. and Zha, T.: 2003, Modest Policy Intervention, Journal of Monetary Economics 50, 1673-1700.

Liu, Z., Waggoner, D. and Zha, T.: 2011, Sources of the Great Moderation: A RegimeSwitching DSGE Approach, Quantitative Economics 2(2), 251-301.

Lubik, T. and Schorfheide, F.: 2004, Testing for Indeterminacy: An Application to U.S. Monetary Policy, American Economic Review 94(1), 190-217.

Lucas, R. E.: 1976, Econometric Policy Evaluation: A Critique, in K. Brunner and A. Meltzer (eds), The Phillips Curve and Labor Markets, Vol. 1 of Carnegie-Rochester Series on Public Policy, Vol. 1, North Holland, Amsterdam.

Primiceri, G.: n.d., Time Varying Structural Vector Autoregressions and Monetary Policy,

The Review of Economic Studies .

Romer, C. D. and Romer, D.: 2002, A Rehabilitation of Monetary Policy in the 1950's, American Economic Review 92(2), 121-127.

Schorfheide, F.: 2005, Learning and Monetary Policy Shifts, Review of Economic Dynamics 8(2), 392-419.

Sims, C. A.: 2002, Solving Linear Rational Expectations Models, Computational Economics $20(1), 1-20$.

Sims, C. A., Waggoner, D. F. and Zha, T.: 2008, Methods for Inference in Large MultipleEquation Markov-Switching Models, Journal of Econometrics 146, 113-144.

Sims, C. A. and Zha, T.: 2006, Were There Regime Switches in US Monetary Policy?, American Economic Review 91(1), 54-81.

Smets, F. and Wouters, R.: 2007, Shocks and Frictions in U.S. Business Cycles: A Bayesian DSGE Approach, American Economic review 97(3), 586-606.

Stock, J. H. and Watson, M. W.: 2003, Has the Business Cycle Changed? Evidence and Explanations, Presented at Monetary Policy and Uncertainty: Adapting to a Changing Economy, Federal Reserve Bank of Kansas City Symposium, Jackson Hole, Wyoming.

\section{A Posterior Mode and Gibbs sampling algorithm}

When working with models whose posterior distribution is very complicated in shape it is very important to find the posterior mode before starting to draw from the posterior. Then, the following Metropolis Sampling within Gibbs can be used to draw from the posterior:

At the beginning of iteration $n$ we have: $\theta_{n-1}^{s p}, \theta_{n-1}^{v o}, S_{n-1}^{T}, \xi_{n-1}^{s p, T}, \xi_{n-1}^{v o, T}, H_{n-1}^{s p}$, and $H_{n-1}^{v o}$.

Step 1 (Sampling the MS states for the stochastic volatilities $\xi_{n}^{v o, T}$ ): Conditional on the DSGE parameters, $S_{n-1}^{T}$ and a sequence for the MS states $\xi_{n}^{s p, T}$, we have a MS-VAR 
with known hyperparameters: $S_{t}=T\left(\xi_{t}^{s p}\right) S_{t-1}+R\left(\xi_{t}^{s p}\right) Q\left(\xi_{t}^{v o}\right) \epsilon_{t}$. Therefore, for given $H_{n-1}^{v o}$, Bayesian updating can be used to derive a filtered estimate of $\xi_{n}^{v o, T}$. Then, the multimove Gibbs-sampling of Carter and Kohn (1994) can be used to draw $\xi_{n}^{v o, T}$.

Step 2 (Sampling the transition matrix $H_{n}^{v o}$ ): Given the draw for the MS state variables $\xi_{n}^{v o, T}$, the transition probability is independent of $S_{n-1}^{T}$ and the other parameters of the model and have a Dirichlet distribution. For each column of $H_{n}^{v o}$ the posterior distribution is given by $H_{n}^{v o}(\cdot, i) \sim D\left(a_{i i}^{v o}+\eta_{i i}^{v o}, a_{i j}^{v o}+\eta_{i j}^{e r}\right)$ where $\eta_{i j}^{v o}$ denotes the numbers of transitions from state $i^{v o}$ to state $j^{v o}$ and $\left(a_{i i}^{v o}, a_{i j}^{v o}\right)$ are the parameters describing the prior.

Step 3 (Sampling the structural DSGE parameters $\theta_{n}^{s p}$ and $H_{n}^{s p}$ ): Draw a new set of parameters from the proposal distribution: $\left[\vartheta_{n}^{s p} ; \widetilde{H}^{s p}\right] \sim N\left(\theta_{n-1}^{s p}, c \bar{\Sigma}^{s p}\right)$. Here $\bar{\Sigma}^{s p}$ is the inverse of the Hessian for the structural parameters computed at the posterior mode and $c$ is a scale factor. If $n=1$, set $\theta_{n-1}^{s p}=\bar{\theta}^{s p}+c \bar{\Sigma}^{s p}$, where $\bar{\theta}^{s p}$ is the posterior mode estimate of the structural parameters. Conditional on the path for the stochastic volatilities regime $\xi_{n}^{v o, T}$ and a set of parameters for the stochastic volatilities $\theta_{n-1}^{v o}$, the modified Kalman filter described in Kim and Nelson (1999) can be used to evaluate the conditional likelihood according to $\theta_{n-1}^{s p}$, the old set of parameters, and $\vartheta^{s p}$, the proposed set of parameters. Then the conditional likelihood is combined with the prior distributions of the DSGE parameters and the proposal vector $\vartheta_{n}^{s p}$ is accepted or rejected according to a Metropolis step.

Step 4 (Sampling the DSGE state vector $S_{n}^{T}$ ): Step 3 returns an (approximate) filtered estimate of the MS states and DSGE state variables: $\widetilde{\xi}_{n-1}^{s p, T} \mid Y^{T}$ and $\widetilde{S}_{n}^{T} \mid Y^{T}$. Use the multimove Gibbs-sampling of Carter and Kohn (1994) to draw a sequence for $\xi_{n}^{s p, T}$ and then, conditional on $\xi_{n}^{s p, T}$ and $\xi_{n}^{v o, T}$, a sequence for $S_{n}^{T}$.

Step 5 (Sampling the stochastic volatilities): Given the draw for the DSGE states $S_{n}^{T}$, the observation errors and the structural shocks become observable. Therefore, conditional on $\xi_{n}^{v o, T}$ and given the assumption of Gaussian distributions, each parameter of the vector $\theta_{n}^{v o}$ can be drawn using an inverse gamma: $\sigma_{x, n} \sim I G\left(s_{0}+s s r_{x}, v_{0}+T\right)$, where $s_{0}$ and $v_{0}$ are the shape and scale parameters implied by the choice for the prior mean and variance, $s s r_{x}$ is the sum of squared residual for the shock of interest $x$, and $T$ is the sample size.

Step 6: If $n<n_{\text {sim }}$, go back to 1, otherwise stop, where $n_{\text {sim }}$ is the desired number of iterations.

\section{B Data set}

As in Fernández-Villaverde et al. (2010), I reconstruct the series consistent with the corresponding economic concepts. Specifically, the relative price of investment is obtained 
Potential Scale Reduction Factor

\begin{tabular}{cc|cc|cc}
\hline \hline Parameter & PSRF & Parameter & PSRF & Parameter & PSRF \\
\hline$\phi_{\pi}\left(\xi^{s p}=1\right)$ & 1.00 & $\rho_{g}$ & 1.00 & $\sigma_{R}\left(\xi^{v o}=1\right)$ & 1.00 \\
$\phi_{\pi}\left(\xi^{s p}=2\right)$ & 1.01 & $\rho_{\zeta_{i}}$ & 1.00 & $\sigma_{R}\left(\xi^{v o}=2\right)$ & 1.00 \\
$\phi_{y}\left(\xi^{s p}=1\right)$ & 1.00 & $\rho_{\zeta_{c}}$ & 1.00 & $\sigma_{\zeta c}\left(\xi^{v o}=1\right)$ & 1.00 \\
$\phi_{y}\left(\xi^{s p}=2\right)$ & 1.00 & $\rho_{\zeta_{\Upsilon}}$ & 1.00 & $\sigma_{\zeta c}\left(\xi^{v o}=2\right)$ & 1.00 \\
$\rho_{R}\left(\xi^{s p}=1\right)$ & 1.01 & $\rho_{\mu_{z}^{*}}$ & 1.00 & $\sigma_{\zeta_{\Upsilon}}\left(\xi^{v o}=1\right)$ & 1.00 \\
$\rho_{R}\left(\xi^{s p}=2\right)$ & 1.01 & $\mu_{z}^{*}$ & 1.00 & $\sigma_{\zeta_{\Upsilon}}\left(\xi^{v o}=2\right)$ & 1.00 \\
\cline { 1 - 1 }$H_{11}^{s p}$ & 1.00 & $\pi^{*}$ & 1.00 & $\sigma_{\mu_{z}^{*}}\left(\xi^{v o}=1\right)$ & 1.00 \\
$H_{22}^{s p}$ & 1.00 & $\left(\beta^{-1}-1\right)$ & 1.00 & $\sigma_{\mu_{z}^{*}}\left(\xi^{v o}=2\right)$ & 1.00 \\
\cline { 1 - 3 }$S^{\prime \prime}$ & 1.00 & $\Phi$ & 1.00 & $\sigma_{g}\left(\xi^{v o}=1\right)$ & 1.00 \\
$\sigma_{A}$ & 1.00 & $\lambda_{f}$ & 1.00 & $\sigma_{g}\left(\xi^{o o}=2\right)$ & 1.00 \\
$\xi_{p}$ & 1.00 & $\log (\Upsilon)$ & 1.00 & $H_{11}^{v o}$ & 1.00 \\
$\iota_{p}$ & 1.00 & $\sigma_{L}$ & 1.00 & $H_{22}^{v o}$ & 1.00 \\
\hline \hline
\end{tabular}

Table 5: The table reports the Gelman-Rubin Potential Scale Reduction Factor (PSRF) for multiple chains of 800,000 draws each (1 every 1000 are stored). Values below 1.1 are regarded as indicative of convergence.

following the methodology described in Fisher (2006). Real GDP per capita is obtained by dividing nominal GDP by the consumption deflator and population. Consumption is defined as the sum of personal consumption expenditures on non-durable goods and services. The series for nominal investment is constructed in a similar way starting from the series for gross investment and durables. Both series are then divided by the consumption deflator. Inflation is measured as the annualized quarterly log-differnece in the consumption deflator. Finally, the FFR is obtained by averaging monthly figures. This last series is downloaded from the St. Louis Fed website, while all the other series are extracted from the NIPA tables.

\section{Convergence}

Table 5 reports results based on the Brooks-Gelman-Rubin potential reduction scale factor using within and between variances based on the five multiple chains used in the paper. The five chains consist of 920,000 draws each, the first 20,000 draws are dropped, and of the remaining draws 1 in every 1,000 draws is saved. The numbers are very close to 1 and therefore well below the 1.1 benchmark value used as an upper bound for convergence. 